\title{
Interplanetary Travel: Cluster Analysis of Inspec Classification Codes to Identify Main Subject Areas
}

\author{
Nestor L. Osorio \\ Northern Illinois University \\ DeKalb, Illinois, USA \\ nosorio@niu.edu \\ Gabriel E. Osorio \\ Northern Illinois University \\ DeKalb, Illinois, USA \\ z966056@students.niu.edu
}

\begin{abstract}
Background. Interplanetary travel is a highly scientific and technological area. Scientific institutions and organizations, government agencies, and the media have made this subject popular. It is also a major aspect of science fiction. An exploration of the subject can be of interest to a wide audience.

Objective. To define the major scientific and technical aspects of interplanetary travel and present them to the non-scientific reader.

Method. Relevant citations on the subject were obtained from the Inspec database using applicable keywords; the bibliography of four key articles and citations were also retrieved from Inspec. All the classification codes from the citations were compiled. The visualization software Sci2 was used to create subject clusters, and the classification codes related to each cluster were extracted. Result. Six main subject areas were found to represent the main components of interplanetary travel. These are described, together with a list of basic resources. Major publications such as books, journals and conference proceedings obtained from the searches are listed.

Contribution. This survey is targeted at librarians, teachers, and others with limited scientific background to provide them with an overview of the scientific and technical aspects of interplanetary travel. This information can be used to prepare information literacy sessions on a topic that can bring active participation and interest in a class. It can help students with non-scientific backgrounds venture into this exciting area. Finally, this can be viewed as a contribution to science literacy.
\end{abstract}

\section{INTRODUCTION}

In the early years of space exploration, Dwight D. Eisenhower's President's Science Advisory Committee (1958) referred to "the compelling urge of man to explore and to discover, the thrust of curiosity that leads men to try to go where no one has gone before.” Interplanetary travel is a topic of interest both in the scientific community as well as in science fiction literature. Evidence shows that throughout all of known history, humans have studied and interpreted the sky and struggled to understand the mysteries of the cosmos (Fix, 2004). The 
stories and beliefs from early mythological and astrological ideas have evolved into serious scientific and technological fields. The remarkable level of precision and quality of today's instruments and data analysis is contributing to better insights into the universe, and the alteration or confirmation of theoretical foundations. Hence this paper is based on the scientific and technological literature that represents these advances. At the same time, science fiction has also been prospering side by side with this extraordinary new knowledge creation. In this paper, we are concerned with the knowledge domains in interplanetary travel, on which a major part of science fiction literature is founded.

This is not a critical analysis or a comprehensive review of the subject. Rather, it is a descriptive exposition based on the results obtained using the Inspec database. Although limited in its scope, the results show interesting information about the components of interplanetary travel. In addition, similar works have been published with the intent of presenting basic information about a scientific subject aimed at librarians, instructors, and students, such as the works of Stankus (2014) on biofuels, Kulp (2014) on genomics, Jarrett (2014) on the Ebola virus, Delwiche (2016) on the Zika virus, and Tran (2016) on particle detectors. Furthermore, a substantial portion of science fiction is based on scientific knowledge; we are not comparing or analyzing the real scientific knowledge with the popular ideas. A better understanding of the real knowledge can be of benefit to science fiction followers.

A second motivation for the selection of this topic is the recent work done by researchers such as E. W. Davis (2006 and 2012) of the Institute for Advanced Studies, Austin, TX; by J. C. Garcia-Escartin and P. Chamorro-Posada (2013) from the Universidad de Valladolid, Departamento de Teoría de la Señal y Comunicaciones e Ingeniería Telemática; and the work of P. Lubin (2016) of the University of California, Santa Barbara, Experimental Cosmology Group. These recent contributions are important to this topic because the authors using the scientific formal communication (papers published in well-recognized proceedings and journals) present specific arguments that make extraordinary long-distance space travel a realistic event in the future. There are many other scientists with remarkable theories about the possibilities of exploring the universe but not necessarily human or robots in spaceships. NASA's Hubble Space Telescope mission is an example of a project that has renewed interest in the study of the universe.

In his first article, Davis (2008) explores faster-than-light (FTL) technological details, analyzes tentative solutions, and concludes that transversable wormholes are better suited for traveling in space since less negative energy is necessary as compared to warp drives. The need for developing a source of negative energy at large scale in space is presented, and the concerns for controlling the lab environment for negative energy experimentation is discussed. The second article by Davis (2012) presents the technical problems to be resolved in order for FTL space warps to be possible, such as the production of large-scale negative energy, the creation of guidance, manipulation, and control principles, the development of a program of space warps computer simulation, and a number of other fundamental theoretical issues. Garcia-Escartin and Chamorro-Posada (2013) proposed a number of technologies expected to recognize the signatures of artificial objects traveling at near the speed of light, which would allow the identification of extraterrestrial civilizations based on the assumption that interstellar ships would leave traces in the universe. Advanced methods of propulsion are assumed. Lubin (2016) proposed a system "that will allow us to take the step to interstellar exploration using directed energy propulsion combined with miniature probes including some where we would put an entire spacecraft on a wafer to achieve relativistic flight and allow us to reach nearby starts in human lifetime.” 
In this study, following established practices of bibliometrics, we identify a body of scientific literature using the Inspec database. The classification codes provided by Inspec are compiled and presented to a visualization procedure of the Sci2 visualization tool. This analysis created subject domain clusters which allow for the identification of the main subject areas pertaining to interplanetary travel.

This study has several objectives:

1. to demonstrate that using heuristic visualization techniques it is possible to identify components (clusters) of a subject;

2. to provide lists of resources of high scientific and technical quality that were obtained as a by-product of searches carried out in Inspec;

3. to present, through the authors' knowledge and extensive reading, selected resources that can be used for increasing readers' awareness about the specific components of interplanetary travel.

This paper is geared towards librarians, instructors and students that are interested in scientific topics but do not have a formal education or training about the subject.

In addition, topics such as interplanetary travel can bring active participation from students in information literacy projects and can contribute to the science literacy of citizens from any country. Basic bibliographic instruction using themes from space traveling or science fiction in general has not been greatly reported in the literature. After extensive searching in databases like LISTA (EBSCO) and Academic Search Complete, only a few articles pertaining to academic libraries were retrieved. The article by Osif (1993) described how science fiction was a component of a library research methodology one-credit course; DiBianco (2005) discussed how literature can be a strategy for increasing students' interest in a subject (math, music, etc.). For example, science fiction can be used to better understand scientific theories and applications. The works of Ontell (2003) and Scott (1980) offered ideas about how science fiction has been used for this purpose. We hope that this survey will serve as an encouragement to use technology-based topics in introductory information literacy projects.

\section{CITATION ANALYSIS AND VISUALIZATION}

Citation analysis has been found to be a useful tool for studying the bibliographic characteristics of a subject. An excellent introduction to the use of bibliometric and citation analysis is the book by De Bellis (2009), Bibliometrics and citation analysis: From the Science Citation Index to cybermetrics. Another basic introductory work is the chapter by Nicolaisen (2007) in the Annual review of information science and technology. The literature of citation analysis is extensive. As indicated by Rosenberg (2015), "A plethora of citation analysis studies allow academic librarians the possibility of sharing their research studies throughout the world and the opportunity of viewing other current research studies from abroad" and then goes on to mention citation studies carried out in academic libraries in Belgium, Canada, China, Croatia, Finland, India, Iran, Nigeria, and Spain. Among several applications of citation analysis, the literature shows that it can determine the impact of a publication, or a research institution; establish linkages among authors of a subject, the importance of the contributions of a researcher, and other significant uses. In this study, we used citation analysis to determine the component areas of a subject domain.

There are many articles reporting citation analysis used for identifying the components of a subject domain, including the work of Braun, Glanzel, Maczelka, and Zsindely (1993) which discussed the literature of Analytical Chemistry, covered by a major chemistry 
abstracting service. The literature of Nursing is analyzed for a three-year period, based on the citations covered by several health sciences databases (Allen, Jacobs \& Levy, 2006). A study about the Information Science literature in China by Hu, Hu, Deng, and Liu (2013) used a cowords analysis and produced 13 clusters of subject terms. The structure of STEM education is studied by Assefa and Rorissa (2013), in which they performed co-word analyses and produced subject clusters. Finally, Nwagwu (2006) determined the coverage of biomedical literature produced in Nigeria by obtaining citation data from Medline, identified leading publications, and established the potential impact of these publications using Thomson's ISI Journal Citation Reports.

Visualization software and procedures are powerful tools used in bibliometric studies. Meirelles (2013), in her work about designing for information, indicates that visualization in the sciences is a means to communicate findings and a "platform for data manipulation and exploration.” Based on cognitive principles, visual displays can be used to record information, facilitate discovery, and to provide a vehicle for data manipulation.

Belter and Seidel (2013) performed a bibliometric analysis of the climate engineering research by creating a bibliographic coupling network showed components of this literature. Boyack, Wylie, and Davidson (2002) used the visualization tool VxInsight to perform a domain analysis for the management of science and technology projects. Using bibliographic citations, the data is subject to statistical procedures that produce clusters of subjects. Chen, Paul, and O'Keefe (2001) studied the discipline of Computer Graphics by collecting data from articles published in the journal IEEE computer graphics and applications. Using several citation analysis techniques, a series of graphics identifying subject domains were obtained. Another interesting study is the survey of Arencibia-Jorge, Vega-Almeida, and Martí-Lahera (2007), which used a multi-step procedure involving several statistical and text mining software. They obtained citation data from the Science Citation Index, identified subject domains as well as performed semantic analysis. These are examples of visualization projects where graphics softwares have been used to analyze subject domains.

\section{RESEARCH METHODOLOGY AND DATA COLLECTION}

\section{Data Sources and Processing}

We followed common practices for data gathering for bibliometric analysis. Our main objective for data collection was to find representative bibliographic information about interplanetary travel. For that purpose, the Inspec indexing and abstracting database was selected since it has strong coverage in physics as well as in electrical and electronic engineering and in computer science. Inspec is a product of the Institution of Engineering and Technology (IET), Stevenage, UK. The EBSCOhost information system was used to search the Inspec database.

The bibliographic data was obtained by searching Inspec from three angles: 1) engineering and technological aspects, 2) warps and wormholes, and 3) citations from four key articles.

The first search explores the technical aspects of interplanetary travel. To accomplish this phase, a preliminary search was done in the Compendex indexing and abstracting database, which has broad coverage of engineering and technology fields. We searched for records related to:

"space travel" OR "interplanetary travel" OR "interstellar travel" 
From the 750 citations retrieved, we collected the following significant subject terms: "space flight" or "spacecraft" or "space research" or "space physics" or "rockets" or "missiles" or "biology" or "chemical products" or "aerospace engineering" or "rocket propulsion" or "satellites" or "military engineering" or "industrial economics" or "mathematics" or "biological materials" or "tissue engineering" or "computer applications" or "solar energy" or solar phenomena" or "chemistry" or "rocket engines" or "management" or "technology on society" or "atomic physics" or "molecular physics" or "aircraft" or "avionics" or "cost engineering" or "industrial economics" or "computer software" or "data handling" or "electronics" or "engineering research" or "accidents" or "accident prevention" or "electromagnetic waves" or "mechanics" or "light optics" or "bioengineering" or "telecommunication" or "radar" or "plasma physics" or "industrial engineering" or "anatomy" or "medicine"

These were combined with the terms "space travel" or "interplanetary travel" or "interstellar travel" using the AND operator. This query retrieved 221 records in Inspec.

A second search looked for citations in Inspec related to warps and wormholes associated with space travel: ((warps or wormhole) AND travel). This produced 64 citations. A third search looked for citations in Inspec that had been cited by Davis (2006 \& 2012), Garcia-Escartin and Chamorro-Posada (2013), and Lubin (2016). Although not all the referenced items were found in Inspec, this search retrieved 169 records or 88.8 percent of all references. The total number of citations obtained with Classification codes was 454, after duplicated citations were discarded.

The preliminary search in Compendex was carried out in order to capture significant subject terms that represent both the physics and engineering aspects of Space Travel. The second search in Inspec was necessary because of the importance of cosmological warps and wormholes as tools for travelling extraordinary long distances through space. As mentioned earlier, the four articles proposed very specific solutions for making extraordinary longdistance space travel a realistic event in the future. Therefore, it was important to include their supporting literature (references). This process of mining the literature of a scientific topic using different perspectives and components is a common practice. Further, we selected Inspec as the base database because of its coverage in both physics and technical areas; Compendex is a very strong engineering database. Also, by using only the Inspec Classification Codes the identification of clusters is consistent (using a single type of descriptive metadata) and easier to access.

An Inspec bibliographic record includes title, author, author affiliation, source, abstract, Inspec descriptors (controlled vocabulary), key phrase headings, classification codes and other fields. For the purpose of data analysis, we concentrated on the title and the classification codes. The title was used mainly for the identification of each citation; our data analysis was based entirely on classification codes. Classification codes assigned by expert indexers to each article in the Inspec database are very powerful metadata elements that identify the main subject areas covered by the article; several Classification codes are assigned to an article. Classification codes are also effective ways to retrieve significant articles on a topic. The data collected was loaded into a Microsoft Excel file and constituted the data source presented to the Sci2 procedures.

\section{Data Analysis}

Science of Science (Sci2) was used for statistical analysis and evaluation of the data. This visualization software package recommended by Cobo, Lopez-Herrera, Herrera-Viedma and 
Herrera (2011) has been used for data analysis in several bibliometric projects and has the advantage of being an open source software. A co-occurrence network for the set of classification codes was constructed. In a co-occurrence network, the associative relation between terms (classification codes) is determined by the frequency with which the pair of terms occur in the same record (i.e. the number of bibliographic records that have been indexed with both classification codes). Next, the Watts and Strogatz (1998) clustering algorithm was applied to the co-occurrence network. This procedure, also known as smallworld networks, is characterized by high clustering coefficients and an average shortest path lengths between pairs of terms (Watts-Strogatz Small World, 2009). A description of the major concepts involved follows.

We used the process of network analysis which is based on a structure of nodes and connecting links or edges. Nodes can represent bibliographic elements such as journal titles, authors, or subject terms. In our case, nodes represent classification codes or subject concepts and the links are the relationships among them (Price, 1965; Van Eck \& Waltman, 2014). The use of classification codes is similar to using keywords because both represent subject concepts. Keywords are usually obtained from the title, the abstract, or a list supplied by the author; classification codes are assigned by indexers from a subject thesaurus. In either case, the number of co-occurrences of two keywords or classification codes represents the frequency of papers where both of them appear (Van Eck \& Waltman, 2014). Subsets can be determined by applying a similarity or distance function to the data under study. The results create subsets with members that are similar to each other's and different to the members of other subsets. A number of algorithms are available for the analysis of the properties of a network. The type of bibliographic setting of our study has the condition for applying smallword networks procedures. For that purpose, we used the Watts-Strogatz Clustering Coefficient (Watts \& Strogatz, 1998), a tool provided by Sci2. Network analysis is used in a variety of problems such as in physics, biometrics, econometrics, sociology and several others. Sci2 makes available tools to study networks occurring in bibliometric studies.

Erdös-Rényi is a very simple model that is not a good predictor of the degree of distribution or clustering formation as compared to real networks. In real networks, a high clustering coefficient is usually found; this means that there is a high likelihood that two members connected at a node are associated. But Erdös-Rényi is characterized with small path lengths (Erdös \& Rényi, 1959; Steen, 2010). Milgram's (1967) famous letters experiment showed that the average path lengths in real-world situations are relatively small; a condition already stabilized in Erdös- Rényi model. At that time, it was also known that in many reallife situations, members of a network (such as people) have the tendency to group in small clusters. The Watts and Strogatz (1998) model has the properties of Erdös-Renyi random graphs, and provides us with large clustering coefficients, which resembles real-world networks.

In the Watts and Strogatz (1998) model, a network has a large number of interconnected nodes characterized by the presence of clusters, in the graph, of nodes located at short distance. Networks with a small average distance and high clustering coefficients are typical in scientific co-occurrence studies (Strobel, et al., 2011). The Watts and Strogatz (1998) model has been proven to be a reliable model but it has its limitations: it assumes a fixed number of nodes. For example, one property not covered by the Watts and Strogatz (1998) model is the condition observed that real networks grow; a process in which new nodes attach themselves to the lattice. These are known as scale-free networks. The Barabási and Albert model (1999) is also used as a procedure for establishing certain preferences in the 
process of attaching new nodes. Further, the study of networks is an active area of research because of its immense possible applications.

The identification of clusters in this study is based on the process of examining a graphic to discover information from the data being graphically presented. Cleveland and McGill (1985 \& 1987), introduced the concept known as graphical perception: "Graphical perception is the visual decoding of the quantitative and qualitative information encoded on graphs." In their work done in the 1980s, ahead of the computer graphics revolution, they argued that the way data is graphically presented has an important impact on its interpretation. Determining methods to study graphical perception was an important part of their research. More recently Meirelles (2013) in her book Design for information shows that the visualization of data from scientific research is a form of presenting research results used for data analysis and manipulation. Other benefits of using a cognitive process of visual analysis include the facilitation of discovery and creation of models from data collected. In our study, after using Sci2 tools to visualize the data collected, we created a model (clusters) based on the concepts of graphical perception and cognitive visual analysis. The results of this process were validated when we examined all the classification codes collected from the searches in Inspec.

\section{RESULTS}

This section has two distinct parts. The first part shows the results obtained using subject classification codes in the determining of the subject components of interplanetary travel. The second part defines each of these components and presents some basic significant publications. This is followed by a list of books, journals, conference proceedings, and reports, as well as a selected list of research institutions and agencies with programs related to space travel.

\section{Analysis of Clusters Obtained From Sci2}

We started by identifying ten clusters of subjects obtained by the previously explained visualization process applied to the 452 articles selected. They contained 502 unique classification codes that were assigned to the records 1,655 times; therefore the average number of classification codes assigned to each record was 3.66.

We have identified ten areas in Figure 1 that can be considered clusters of classification codes due to the close distance of the codes in each cluster. Appendix 1 lists the classification codes extracted from each of these clusters (see columns 1 and 2 of the table in Appendix 1). It is important to note how this analysis was done. The Sci2 visualization tool used allows for the magnification of the graph to a scale where the nodes with each classification code can be clearly distinguished as well as the distance between the nodes. Therefore, as indicated in the previous section, the analysis of the graph was based on graphical perception and cognitive visual analysis. Within each cluster, some concentrations of classification codes are present: for example: in cluster 1, A4200s, B4300s and B6000s; in cluster 2, A9600s; in cluster 3, A4200s, A9500s, and A9600s; in cluster 4, A0400s; in cluster 6, A8600s and B1000s; in cluster 10, A6800s and A8100s. The significance of this type of grouping is that those concentrations of classification codes represent scientific and technical topics in each group that have meaningful relationships. Examples include: in cluster 1: optics, lasers and masers, and electronic communication; in cluster 3: optics, fundamental astronomy and astrophysics, and the solar system; in cluster 6: energy research, and circuit theory, electronic circuits, and 


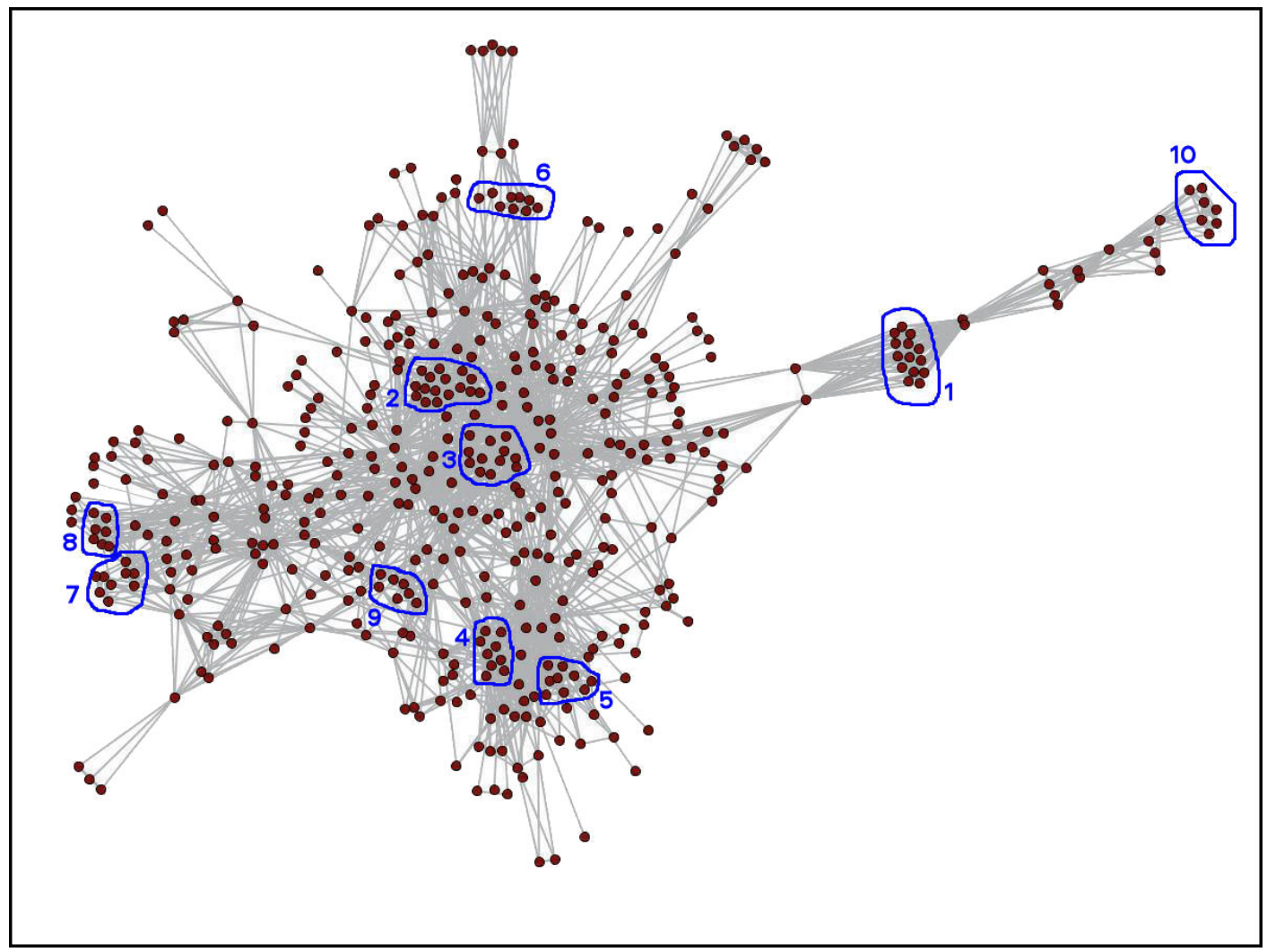

Figure 1. Co-occurrence network of classification codes showing cluster distribution

microwave technology; in cluster 10: surfaces and interfaces, thin films and whiskers, and materials science.

In Appendix 1, codes from the ten clusters are collected, listed in alphanumerical order, and grouped by sections to provide a better perspective of the components of the visualization process. In addition, since we are exploring the major components from the codes extracted, the codes of the subject areas identified are then analyzed at categories of higher level (see Appendix 1 table, column 4). This was done by observing the lists of lower-level categories present in meaningful groups (indicated in column 3) which were then identified as members of a higher level category. In column 4, the codes representing the members of each higherlevel category are marked with six different colors. Furthermore, based on the authors' knowledge of the scientific literature, a label was given to each major group.

The resulting major components obtained from this process are:

1. Astrophysics

2. Relativity and quantum fields

3. Biophysics and medical physics

4. Aerospace engineering

5. Electronics and communications

6. Materials and condensed matter

We also analyzed all classification codes cited in the 452 original documents and counted the number of times they occurred (frequency). When 60 percent of the most frequent classification codes from the 1655 codes assigned were analyzed, it showed the presence of four of the above topical areas: Astronomy, Relativity and Quantum Fields, Biophysics and Medical Physics, and Aerospace Engineering, (see Appendix 1 table, column 5). Therefore, 
we can conclude that the six major cluster areas obtained from the visualization tool are reasonable.

The description of each field includes bibliographic sources that can be of value to students and librarians. A variety of sources have been included from encyclopedias and handbooks to textbooks and popular bestsellers. Selection of these materials is based on a process used by the authors of this project when identifying sources that teach or present information to the non-technical audience. It was not an easy task since these are highly technical topics. The following three sources are encyclopedias with extended coverage that can be used for almost any topic related to interplanetary travel:

- McGraw-Hill encyclopedia of science and technology (2012), published by McGraw-Hill Education, is a 20-volume reference source that provides information in all the major disciplines of science and technology.

- AccessScience (2000) is the online version of McGraw-Hill encyclopedia of science and technology with additional features and is updated regularly. It also includes the content of McGraw-Hill education yearbook of science and technology and the McGraw-Hill dictionary of scientific and technical terms.

- Encyclopedia of space science \& technology by Hans (2003) is a two-volume work that summarizes an entire scientific and technological field. It is a good source for basic information.

It is common practice in academic libraries and research institutions to have staff members that are specialists in specific subjects. These librarians commonly known as subject librarians, subject specialists, or bibliographers, have the bibliographic knowledge required for tasks such as materials selection, bibliographic instruction, and authoring annotated bibliographies. In fact, librarians publish many annotated bibliographies and webliographies in the form of articles and books annually. The principal author of this paper is an experienced subject librarian, with academic degrees in the sciences while the second author has a background in science and engineering. The main challenge when selecting sources for this paper was that most of the published scientific and technical literature was written by experts for science and engineering students and researchers. We have selected secondary and tertiary resources from which a person with scientific curiosity but lacking the proper scientific foundation can obtain some solid background of these subjects. Selecting these materials was time-consuming. We do not expect that the entire reading of these sources will be necessary, in most cases reading the introductory chapter or the introduction of some chapters will provide the reader with what they need. This way of presenting a subject to a less knowledgeable audience is common practice in science and engineering librarianship. See, for example, publications such as: Issues in science and technology librarianship, science and engineering libraries, the Journal of the Medical Library Association, and Collection building. We have also found that popular non-fiction bestsellers that cover scientific topics are very valuable sources. As they are also written by experts, they often provide a less rigorous introduction to these subjects. Hence, we have selected a few as representative of this genre. The basic criteria for selection were:

1. scientific and technical encyclopedias and handbooks;

2. introductory texts;

3. introductory chapters and or introductory sections in chapters for texts which are more advanced; and

4. non-fiction best sellers. 
These principles were used for all sections of the following main components of interplanetary travel. The tables in the Resources section were obtained straight from the 454 items used in the visualization analysis.

\section{MAJOR COMPONENTS OF INTERPLANETARY TRAVEL}

\section{Astrophysics}

Astrophysics encompasses the study of the universe, and the description and interpretation of its phenomena. Through observations, phenomena are interpreted based on extensive data collection and statistical analysis. This allows the determination of how they evolved; it also allows for the comparison to other phenomena. Some topics include black holes, quasars, neutron stars, galaxy clusters, and dark matter (Rigden, 1996).

Citations on Astrophysics and related areas cover topics such as: Relativity and Gravitation in Astrophysics; Astronomical and Space-research Instrumentation; Aerospace Instrumentation; Lunar, Planetary, and Deep-space probes; Astronomical Techniques; Other topics in astronomy and astrophysics; Black Holes; Background Cosmic Radiations; Cosmology; Theoretical Cosmology; Stars; Stellar systems, Galactic and Extragalactic Objects and Systems, Universe; Aeronomy, Space Physics; Cosmic Rays; Fundamental Astronomy and Astrophysics, Instrumentation and Techniques and Astronomical Observations.

The following are sources that can provide a better understanding of this scientific field:

- The Encyclopedia of astronomy and astrophysics, edited by Paul Murdin (2001) from the Particle Physics and Astronomy Council of the British National Space Center, is a comprehensive four-volume set written by several hundred experts. It is a good source for basic information. The reader will find information about comet tails or starburst galaxies in an easy to read style.

- Zombeck's (2007) Handbook of space and astrophysics, although written for graduate students and space researchers, presents a broad spectrum of the subject, including tools, data and information such as radiation issues, detectors, and launch vehicles.

- Cosmology and particle astrophysics, by Bergström and Goobar (2004), is a book for physics majors. However, readers who are not physics-inclined will benefit from reading the introduction of almost every chapter as they acquire an understanding of the fundamental issues of particle astrophysics.

- Clark's (1999) Towards the edge of the universe: A review of modern cosmology is a book for those who like science and are willing to make an effort to understand cosmology; the author used findings from the Hubble Space Telescope in presenting the material. Clark is a Fellow of the Royal Astronomical Society and author of the Guardian blog Across the universe.

- Planetary sciences of De Pater and Lissauer (2015) is a textbook and a winner of an astronomical writing award. This book can give the non-specialist reader an overview of the main topics of planetary sciences. Although the writing is highly technical, readers can skim over or skip the heavy scientific presentation and still appreciate the subject.

- Written as a first-year textbook for students of science and engineering, Adventures in celestial mechanics (Szebehely \& Mark, 1998) provides the reader with a large number of examples in which celestial mechanical principles are applied. 
- The 170 pages of Astrophysics: A primer by Kundt (2001) summarizes basic qualitative and quantitative tools needed for the interpretation of astrophysical phenomena.

Among popular bestsellers are: Kaku's (2006) Parallel worlds: A journey through creation, higher dimensions, and the future of the cosmos; Greene's (2005) The fabric of the cosmos: Space, time, and the texture of reality; and also Greene's (1999) The elegant universe: Superstrings, hidden dimensions, and the quest for the ultimate theory. Also a bestseller, Cosmos, written by scientist, writer and producer Carl Sagan (1980), summarized the 13-episodes of the award-winning television series Cosmos: A personal voyage. Written with Ann Druyan and Steven Soter, it presents the story of the universe and the development of science.

\section{Relativity and Quantum Fields}

General relativity studies the interaction of gravitational fields with objects in motion and light; special relativity deals with the motion of matter and radiation in non-gravitational environments. Quantum field theory describes systems such as electromagnetic fields as determined by the laws of quantum mechanics (Rigden, 1996). In addition, quantum electrodynamics studies the representation under the principles of relativity and quantum mechanics of electromagnetic radiation as interacting with electrically charged matter (McGraw-Hill encyclopedia of science and technology, 2012).

Under relativity and quantum fields, the results from the Inspec's searches include the following areas: Special Relativity; Quantum Theory, Quantum Mechanics; Foundations, Theory of Quantum Measurement, Miscellaneous Quantum Theories; General Relativity; Fundamental Problems and General Formalism in General Relativity; Solutions to Equations in General Relativity; Continuous Media; Electromagnetic and Other Mixed Gravitational Systems; Alternative Theories of Gravitation; Quantum Theory of Gravitation; Physics of Black Holes; Quantum Field Theory; Gauge Field Theories. This is not a complete list of topics and the resources listed next are intended to give the reader a broader perspective of the materials covered.

The following sources are recommended.

- The Encyclopedia of physics, edited by Lerner and Trigg (2005), is a comprehensive reference work with more than 500 articles written by experts, covering current topics such as quantum field theory, quantum fluids, quantum mechanics, quantum optics, and quantum statistical mechanics; the formation of stars and planets, quantum communication, space science and technology, and many others. This is an excellent source to start learning about a fascinating science field.

- Discovering relativity for yourself (Lilley, 1981) is a good introduction to the basic concepts of general relativity and the special theory of relativity. Minimum mathematical expertise is required but the author indicates that active reading is necessary as well as working on the problems presented.

- Black holes: The edge of space, the edge of time (Sullivan, 1979) offers an interesting coverage of black holes using a nontechnical approach; it introduces concepts such as warps and wormholes. This book can be used as initial readings or exploration on the subject.

- Galaxies in turmoil: The active and starburst galaxies and the black holes that drive them (Kitchin, 2007) is an appropriate reading for those interested in understanding the formation of galaxies and their composition; it provides a non-mathematical approach to exciting scientific topics. 
Quantum mechanics is a challenging subject, and most books in academic libraries are for physics majors. Our choice of Quantum physics of atoms, molecules, solids, nuclei, and particles of Eisberg and Resnick (1985), requires lower-level undergraduate college mathematics to follow the material. In contrast, Relativistic flight mechanics and space travel: a primer for students, engineers, and scientists by Tinder (2007) is significantly easier to read and understand despite containing technical details. Its approach is to summarize what is known about space travel and explore the possibilities of what is not known. This book covers sections of relativity and quantum fields as well as aerospace engineering.

Some popular bestsellers are: Collier's (2014) A most incomprehensible thing: Notes towards a very gentle introduction to the mathematics of relativity; Quantum field theory for the gifted amateur of Lancaster and Blundell (2014); and Quantum mechanics: The theoretical minimum by Susskind and Friedman (2014). Among many of Stephen Hawking's (1988) excellent works, we have chosen A brief history of time: From the big bang to black holes, in which the author explores fundamental questions about the universe.

\section{Biophysics and Medical Physics}

Medical physics includes the use of radiation in treatments, diagnostic imaging, nuclear medicine, radiation protection, the use of ultrasound, ultraviolet, radiofrequency, and laser radiation. Biophysics is the body of knowledge from chemistry, biology, physics, and mathematics characterized by creating theories, models and technologies to understand life. Typical applications are found in aerospace medicine such as the effect of environment of flight, the effect of weightlessness, and radiation hazards (Rigden, 1996).

In these two areas, the following classification codes were identified in our cluster analysis: Biophysics, Medical Physics, and Biomedical Engineering; Interactions With Radiations at the Biomolecular Level; Cellular Biophysics; Biological Effects of Ionizing Radiations (UV, X-Ray, Gamma-Ray; Particle Radiation Effects); Radiation Dosimetry in Medical Physics; Aerospace Biophysics and Medical Physics (Effects of Accelerations, Weightlessness and Environment); Patient Diagnostic Methods and Instrumentation; Medical Physics and Biomedical Engineering.

For a better understanding of these areas, the following sources are recommended:

- The new physics for the twenty-first century, edited by Fraser (2006), is presented in an encyclopedic format and style. It brings to the reader many of the basic topics related to space travel. Adopting an easy-to-read approach, this work has chapters on "matter and the universe”, "quantum matter”, and sections on biophysics, medical physics and physics of materials, and presents an excellent introduction for the general reader.

- Space physiology and medicine (Nicogossian, Huntoon, \& Pool, 2003) is considered to be a general reference manual that included substantial basic details on the foundations of space medicine and presents the results of human and animal experimentations.

- Fundamentals of space medicine, is authored by Gilles Clément (2011) of the International Space University, Strasbourg, France, who has participated in many experiments related to space missions particularly the International Space Station. It is a great source of information in a readable style.

- Space physiology by Buckey (2006) contains very practical biomedical issues for space explores such as: bone and muscle loss, psychosocial support, radiation hazards, safety, balance and motion sickness, cardiovascular issues; nutrition, long-duration flight medical planning, and flight preparation and recovery. 
- Trailblazing medicine: Sustaining explorers during interplanetary missions, by Seedhouse (2011), emphasizes what is needed to keep a crew alive in a space mission; he discusses topics such as surgical robots, telemedicine, remote emergency care, human hibernation, euthanasia, sex, precautionary surgery and many other challenges for longmission astronauts.

- Edited by four experts in space medicine, Fundamentals of aerospace medicine (Davis, Johnson, Stepanek, \& Fogarty, 2008) is a comprehensive work in space medicine, including a number of clinical aspects such as cardiovascular medicine, dental considerations, endocrine system and nephrology, infectious diseases, neurology, ophthalmology, otolaryngology, psychiatry, and respiratory diseases.

- Mahaling (2009) has compiled a substantial amount of basic information in A-Z biological physics. The study of biological physics has an important role in space projects; this book covers in simple language selected complex topics and procedures.

- Diagnostic nuclear medicine, by Schiepers and Allen-Auerbach (2006), is an example of many in the medical literature that discusses the use of very sophisticated technology for the diagnosis and treatment of illnesses. It is expected that in long-mission space travels, technology of this level would be commonplace.

- The Index of international publications in aerospace medicine, authored by Antuñano (2010) and published by the Federal Aviation Administration, is comprehensive in scope, with international coverage of aerospace medicine, and is an excellent source for those interested in finding more literature in this field.

\section{Aerospace Engineering}

Aerospace engineering is an engineering specialization concerned with aerospace vehicles, their design, structures, flight dynamics, construction, testing, flight performance, operational safety, propulsion systems, and evaluation. It includes aircraft, space vehicles, rockets, satellites, and missiles.

The analysis of the clusters obtained from the visualization procedure produced the following classification codes: Aerospace Facilities and Techniques; Sonics and Ultrasonics; Generating Stations and Plants; Direct Energy Conversion and Energy Storage; Energy Research and Environmental Science; General Aspects of Aircraft, Space Vehicles and Satellites; Aerospace Propulsion; Aerospace Control; Aerospace Engineering Computing; Engines; and Aerospace Industry.

The following are sources can provide information about this highly-technical field:

- The standard handbook for aeronautical and astronautical engineers, edited by Davies (2003), provides insightful and practical guidance on the extensive field of aeronautical engineering in sixteen sections. A recommended reference guide, the handbook includes sections on aerospace structures; rockets and launch vehicles; aeronautical design; spacecraft; aircraft safety and many more; with many illustrations, diagrams, charts, and graphs.

- Spacecraft systems engineering, by Fortescue, Stark and Swinerd (2011), presents a systems design approach to spacecraft development and space missions. Although it is a technical book, the general reader can benefit from discovering the complexity involved in an intense scientific and technological enterprise.

- Now in its eighth edition since its first in 1949, Rocket propulsion elements by Sutton and Biblarz (2011) is considered one of the most popular and the enduring textbooks in aerospace engineering. By skimming through the content, the general reader can acquire 
some basic concepts and technologies and gain an appreciation of spacecraft development.

- Fundamentals of astrodynamics and applications, by Vallado and McClain (2013), is a well-known highly-technical book, but many chapters contain good introductions to the topics as well as considerable historical background which can give readers a basic understanding of the subject.

- Aerospace engineering on the back of an envelope, by Alber (2012), is a compendium of five case studies that demonstrate the method used by engineers when estimating the parameters of complex systems. These case studies, all dealing with aerospace problems and solutions, provide the reader with the experience of analyzing these types of problems.

- The jet engine, prepared by the staff of Rolls-Royce (2015), is a simple and practical exposition of the underlying principles of one of the most complex technologies.

- The international handbook of space technology, by Macdonald and Badescu (2014), is a comprehensive yet accessible work that provides readers with a basic understanding of issues of space technology, such as communications, data systems, descent and landing, launch systems, power, propulsion, robotics, software, structures, and thermal systems.

- In addition, Cumpsty and Heyes (2003) are the authors of Jet propulsion: A simple guide to the aerodynamics and thermodynamic design and performance of jet engines which is an introductory text for the design of aircraft engines.

\section{Electronics and Communications}

Electronics is a field of technology with two major components: Analog Electronics and Digital Electronics. It includes circuit design and electronic/analog devices. Its purpose is the creation of useful applications by analyzing changes in voltages and electric current through the use of other devices. According to the McGraw-Hill encyclopedia of science and technology (2012), Telecommunications Engineering covers a large number of applications, such as transmission lines; networks and networks design; communications methods, protocols, telephony, and videoconferencing; signaling; terminals; traffic analysis, digital data; remote control and telemetry.

This is another area identified as a major component of space travel; it includes the following classification codes: Circuit Theory and Circuits; Circuit Theory; Electronic Circuits; Microwave Technology; Optical Materials and Applications, Electro-Optics and Optoelectronics; Optical Materials and Devices; Lasers and Masers; Communications; Information and Communication Theory; Telecommunication; Radar and Radio Navigation; Laser Optical Systems; Optical Elements, Devices and Systems.

Suggested sources are the following:

- The Wiley encyclopedia of electrical and electronics engineering (Webster, 1999) and its Supplements are a formidable and comprehensive work covering all aspects of electrical and electronics engineering. Highly recognized as a reference source, the 24 volumes of this work provide the reader with basic information of almost any field.

- Electrical circuit theory and technology by Bird (2014) is an introductory textbook with a practical approach of the subject which allows the readers to develop an understanding of fundamental techniques and principles without the heavy and abstracted theoretical details. 
- Penttinen's (2015) The telecommunications handbook presents information appropriate for acquiring a basic understanding of fixed, mobile, and satellite communication systems. It adopts a practical approach necessary for real-world deployments.

- The Introduction to laser technology (Hitz, Ewing, \& Hecht, 2012) is a basic reference source for this topic. As stated in its introduction, the purpose of this book is to demonstrate how a laser works and how it can be used for practical purposes. The authors present the material in a way that keeps mathematical details of quantum electronics to a minimum. The fundamentals are presented in the first ten chapters, followed by another ten chapters focusing on applications.

- The Encyclopedia of laser physics and technology (Paschotta, 2008) is a very good resource for finding brief descriptions of laser physics and technology such as blue lasers or the Kerr effect. Some other topics are discussed in more detail as appropriate. It is geared for researchers; the general reader can find the 700 entries of this source very useable. A free version can be accessed online (Encyclopedia of laser physics and technology, n.d.)

- The Encyclopedia of optical engineering (Driggers, 2003) is a reliable source of information on optical engineering, with over 300 entries written by experts. This encyclopedia which facilitates reader comprehension is packed with figures, photographs, tables, and equations. While technically oriented, the introduction in each section offers the reader an overall summary of each topic.

- Siciliano and Khatib (2016) are the editors of the Springer handbook of robotics, a reference work that presents a comprehensive compilation of classic and emerging application areas of robotics such as: Robotics Foundations; Design; Sensing and Perception; Manipulation and Interfaces; Moving in the Environment; Robots at Work; and Robots and Humans.

\section{Materials and Condensed Matter}

In addition to the study of solid matter, condensed matter physics includes the study of quantum liquids, liquid crystals, porous materials, and gels, among others. Superconductors fall into this area of physics too. Materials science includes the study of metals and ceramics, polymers, composites and semiconductors. The processing of materials for the development of useful applications is an important component of this area (Rigden, 1996).

Materials science and condensed matter are two other important aspects of space projects. The classification codes obtained are: Condensed Matter: Structure, Thermal and Mechanical Properties; Materials Science; Mechanical and Acoustic Properties of Condensed Matter; Physical Chemistry; Structure of Liquids and Solids; Crystallography; and Surfaces and Interfaces; Thin Films and Whiskers.

Sources that can provide a better understating of these two areas are listed below:

- Encyclopedia of condensed matter physics, edited by Bassani, Liedl and Wyder (2005), is an extended presentation of the physical properties of condensed phases of matter. Many of these properties and applications are essential in space projects. This six-volume encyclopedia is a good resource for the understanding of these aspects of physics; it has sections on: acoustics, biophysics, combinatorial catalysis, crystal binding, crystal defects, crystal growth, crystallography, dielectric properties, electrical properties, electrodynamics, electronic structure, instruments/devices, lattice dynamics, magnetic properties, materials processing, mechanical properties, micro-electro-mechanical systems, microscopy, nanostructured materials, optical properties, optics, particle sources, 
plasma, quantum mechanics, radiation sources, scattering, semiconductors, spectrometry, spectroscopy, structures, superconductivity, superfluidity, thermodynamics, and transport properties.

- Encyclopedia of applied physics, edited by Trigg, Vera, Greulich and Immergut (1999), is a great effort for presenting the applications of physics; this 12-volume encyclopedia covers basic methods of all applied and technical areas of physics with real-world applications. The more than 700 articles present applications of laser physics, solid state, semiconductors, biophysics, atomic and nuclear physics. The online version is regularly updated.

- The physics of solids (Turton, 2000) is an introductory textbook on solid state physics without the rigorous mathematical and quantum treatment of the subject. It covers most of the standard topics included in a first year course and is intended for students that need an early exposure to solid state physics.

- Understanding solid state physics (Holgate, 2010) is a textbook for an introductory course; it presents the material with minimal mathematical formulation and covers the basic principles of solid state physics and their applications to the real world. The author is a physicist and journalist.

- The CRC materials science and engineering handbook, edited by Shackelford and Alexander (2001), is considered to be one of the most reliable and comprehensive sources for property data for alloys, ceramics, composites, glass, metals, and polymers. Although it provides rather technical information, the general reader can scan the vast number of possible applications.

- The Encyclopedia of materials: Science and technology, edited by Buschow (2001), is a good resource that shows how the study of electronic, optical, magnetic, or mechanical properties of materials is essential for the use of novel materials in adaptations of new technologically based products and applications. This extensive encyclopedia covers four major aspects of materials science: applications, materials, properties, and techniques and processing.

- The Handbook of material science research (Renard \& Turcotte, 2010) is an interesting book that covers cutting-edge research in 16 significant areas in materials science.

\section{RESOURCES}

\section{Books}

Table 1 lists books published from 1995 to 2015 retrieved by the database searches and from the references of the four articles mentioned earlier. Earlier books are listed in Appendix 2.

\section{Journals}

The literature of space travel covers several science, engineering, medical, and technical areas. The journals presented in Table 2 correspond to the professional journals most often found in the citations and references obtained from the searches done in Compendex for this study.

\section{Conference Proceedings}

The conference proceedings retrieved in the database searches in Compendex are listed in Appendix 2. 


\section{Web Sources}

Table 3 lists selected agencies, professional and research organizations, and educational sources. They were selected based on the authors' knowledge of the scientific literature. It is a representative list.

Table 1. Books cited with publication date from 2015 to 1995

\begin{tabular}{|c|c|c|}
\hline Author. Title & Publisher & Date \\
\hline $\begin{array}{l}\text { Pelton, J. N.; Allahdadi, F. (editors). Handbook of Cosmic } \\
\text { Hazards and Planetary Defense. }\end{array}$ & Springer & 2015 \\
\hline $\begin{array}{l}\text { Long, K. F. Deep Space Propulsion: A Roadmap to } \\
\text { Interstellar Flight. }\end{array}$ & Springer & 2012 \\
\hline $\begin{array}{l}\text { Musha, T.; Minami, Y. Field propulsion system for space } \\
\text { travel: physics of non-conventional propulsion methods for } \\
\text { interstellar travel. }\end{array}$ & Bentham Books & 2011 \\
\hline $\begin{array}{l}\text { Leonhardt, U. Essential Quantum Optics: From Quantum } \\
\text { Measurements to Black Holes. }\end{array}$ & $\begin{array}{l}\text { Cambridge } \\
\text { University Press }\end{array}$ & 2010 \\
\hline Raine, D.; Thomas, E. Black Holes: An Introduction. & $\begin{array}{l}\text { Imperial College } \\
\text { Press }\end{array}$ & 2010 \\
\hline $\begin{array}{l}\text { Bordag, M.; Klimchitskaya, G. L.; Mohideen, U.; } \\
\text { Mostepanenko, V. M. Advances in the Casimir Effect. }\end{array}$ & $\begin{array}{l}\text { Oxford University } \\
\text { Press }\end{array}$ & 2009 \\
\hline $\begin{array}{l}\text { Millis, M.; Davis, E. (editors). Frontiers of propulsion } \\
\text { science. }\end{array}$ & $\begin{array}{l}\text { American Institute of } \\
\text { Aeronautics and } \\
\text { Astronautics }\end{array}$ & 2009 \\
\hline $\begin{array}{l}\text { Vulpetti, G.; Johnson, L.; Matloff, G.L. Solar Sails: A Novel } \\
\text { Approach to Interplanetary Travel. }\end{array}$ & Springer-Praxis & 2008 \\
\hline $\begin{array}{l}\text { Tinder, R. Relativistic flight mechanics and space travel: a } \\
\text { primer for students, engineers, and scientists. }\end{array}$ & $\begin{array}{l}\text { Morgan \& Claypool } \\
\text { Publishers }\end{array}$ & 2007 \\
\hline Keel, W. The Sky at Einstein's Feet. & Springer & 2006 \\
\hline Drummond, P. D.; Ficek, Z. (editors). Quantum squeezing & Springer-Verlag & 2004 \\
\hline Novello, M.; Visser, M.; Volovik, G. Artificial black holes & $\begin{array}{l}\text { World Scientific } \\
\text { Publishing }\end{array}$ & 2002 \\
\hline Davies, P. C. W. How to Build a Time Machine & Penguin Books & 2001 \\
\hline $\begin{array}{l}\text { Gott, J. R. Time Travel In Einstein's Universe: The Physical } \\
\text { Possibilities Of Travel Through Time }\end{array}$ & Houghton Mifflin & 2001 \\
\hline $\begin{array}{l}\text { Milton, K. A. The Casimir Effect: Physical Manifestations of } \\
\text { Zero-Point Energy }\end{array}$ & World Scientific & 2001 \\
\hline Cox, A.N. Allen's Astrophysical Quantities, 4th ed. & Springer-Verlag & 2000 \\
\hline Matloff, G.L. Deep-Space Probes & Springer-Praxis & 2000 \\
\hline $\begin{array}{l}\text { Nahin, P. J. Time Machines: Time Travel in Physics, } \\
\text { Metaphysics, and Science Fiction, 2nd ed. }\end{array}$ & AIP Press & 1999 \\
\hline Pickover, C. Time: A Traveler's Guide & $\begin{array}{l}\text { Oxford University } \\
\text { Press }\end{array}$ & 1999 \\
\hline Novikov, I. D. The River of Time & $\begin{array}{l}\text { Cambridge } \\
\text { University Press }\end{array}$ & 1998 \\
\hline Dirac, P. A. M. General Theory of Relativity & $\begin{array}{l}\text { Princeton University } \\
\text { Press }\end{array}$ & 1996 \\
\hline Visser, M. Lorentzian Wormholes: From Einstein to Hawking & AIP Press & 1995 \\
\hline
\end{tabular}


Table 2. Top journals cited

\begin{tabular}{ll}
\hline Title & Publisher \\
\hline Physical Review D & American Institute of Physics, College Park, MD \\
\hline AIP Conference Proceedings & American Institute of Physics, College Park, MD \\
\hline $\begin{array}{l}\text { Journal of the British } \\
\text { Interplanetary Society }\end{array}$ & British Interplanetary Society, London, England \\
\hline Proceedings of the SPIE & SPIE, Bellingham, WA \\
\hline Classical and Quantum Gravity & IOP Publishing, Bristol, England \\
\hline Advances in Space Research & Elsevier Science Ltd., Oxford, England \\
\hline American Journal of Physics & American Institute of Physics, College Park, MD \\
\hline Physical Review Letters & American Physical Society, College Park, MD \\
\hline Radiation Research & Radiation Research Society, Oak Brook, IL \\
\hline Acta Astronomica & Copernicus Foundation for Polish Astronomy, Warsaw, Poland \\
\hline Nature & Nature Publishing Group, London, England \\
\hline Physical Review A & American Institute of Physics, New York, NY \\
\hline EPJ Web of Conferences & EDP Sciences, Paris, France \\
\hline Modern Physics Letters A & World Scientific Publishing Co., Singapore \\
\hline Physics Letters & Elsevier Science, Amsterdam, Netherlands \\
\hline Science & American Association for the Advancement of Science, \\
\hline Scientific American & Washington, D.C. \\
\hline Astrophysical Journal Supplement & Springer Nature, New York, NY \\
\hline Energiewirtschaftliche Tagesfragen & University of Chicago Press, Chicago, IL \\
\hline Journal of Spacecraft and Rockets & ETV Energieverlag GmbH, Essen, Germany \\
\hline & American Institute of Aeronautics and Astronautics, \\
\hline
\end{tabular}

\section{CONCLUSION}

We have used Inspec as the primary source for collecting data, concentrating on classification codes assigned to each document found. Based on the knowledge we have of the subject coverage of Inspec, we performed an auxiliary search in Compendex in order to collect meaningful terminology from an exclusive engineering index and used those terms to diversify and enrich the search in Inspec. The references included in four articles about space traveling were added because of their unique approach to interplanetary travel technology. The total number of citations obtained from this process was 452; they contained 502 unique classification codes that were assigned to the records 1,655 times.

Using the visualization procedure available from Sci2, and the techniques of analyzing a graph by graphical perception and cognitive visual analysis, the results obtained were acceptable. The graphical perception and cognitive visual analysis approach is an unorthodox approach in cluster analysis which is typically carried out by measuring clustering coefficients and distance factors between the nodes of a network. Nevertheless, when our cluster results were compared with the 60 percent frequency of all classification codes, the comparison was favorable. This unorthodox approach was used because of the limitations that Sci2 has in producing reports of numerical data; Sci2 is essentially visualization software.

We graphically identified ten clusters with concentrations of classification codes having distinct subject coverage. Since our purpose was to identify the major subject components of interplanetary travel, we proceeded to collate all the data obtained from the ten clusters into one table. Upon further study of the table, we discovered six concentrations of 
Table 3. Web resources

\begin{tabular}{|c|c|}
\hline Name & Website/Address \\
\hline $\begin{array}{l}\text { Across the Universe, a Guardian blog } \\
\text { owned by Stuart Clark }\end{array}$ & $\begin{array}{l}\text { https://www.theguardian.com/science/across-the- } \\
\text { universe }\end{array}$ \\
\hline $\begin{array}{l}\text { American Institute of Aeronautics and } \\
\text { Astronautics }\end{array}$ & http://www.aiaa.org/ \\
\hline $\begin{array}{l}\text { Association for Unmanned Vehicle Systems } \\
\text { International (AUVSI) }\end{array}$ & http://www.auvsi.org/home \\
\hline Biosphere 2 (The University of Arizona) & http://biosphere2.org/ \\
\hline China National Space Administration & http://www.cnsa.gov.cn/ \\
\hline $\begin{array}{l}\text { Departamento de Teoría de la Señal y } \\
\text { Comunicaciones e Ingeniería Telemática }\end{array}$ & $\begin{array}{l}\text { Universidad de Valladolid, Escuela Técnica } \\
\text { Superior de Ingenieros de Telecomunicación, } \\
\text { Campus Miguel Delibes, Paseo Belén 15. } 47011 \\
\text { Valladolid, España } 983423660\end{array}$ \\
\hline European Space Agency (ESA) & $\underline{\text { http://www.esa.int/ESA }}$ \\
\hline $\begin{array}{l}\text { Experimental Cosmology Group, University } \\
\text { of California, Santa Barbara }\end{array}$ & http://www.deepspace.ucsb.edu/ \\
\hline Goddard Space Flight Center (NASA) & http://www.nasa.gov/goddard \\
\hline $\begin{array}{l}\text { Hayden Planetarium / Rose Space Center } \\
\text { (American Museum of Natural History) }\end{array}$ & $\begin{array}{l}\text { http://www.amnh.org/our-research/hayden- } \\
\text { planetarium }\end{array}$ \\
\hline Hubble Telescope / HubbleSite & http://hubblesite.org/ \\
\hline $\begin{array}{l}\text { IEEE Aerospace and Electronic Systems } \\
\text { Society }\end{array}$ & http://ieee-aess.org/ \\
\hline Indian Space Research Organisation, ISRO & http://www.isro.gov.in/ \\
\hline Institute for Advanced Studies & $\begin{array}{l}11855 \text { Research Blvd, Austin, TX 78727, (512) } \\
346-9947\end{array}$ \\
\hline International Space Station / NASA & $\begin{array}{l}\text { http://www.nasa.gov/mission_pages/station/main/ } \\
\text { index.html }\end{array}$ \\
\hline Japan Aerospace Exploration Agency & http://global.jaxa.jp/ \\
\hline Marshall Space Flight Center (NASA) & $\begin{array}{l}\text { http://www.nasa.gov/centers/marshall/home/index } \\
\text { html }\end{array}$ \\
\hline $\begin{array}{l}\text { NASA: National Aeronautics and Space } \\
\text { Administration }\end{array}$ & http://www.nasa.gov/ \\
\hline Planetary Society & http://www.planetary.org/ \\
\hline $\begin{array}{l}\text { Roscosmos Space State Corporation } \\
\text { (Russia) }\end{array}$ & http://en.roscosmos.ru/ \\
\hline Royal Aeronautical Society & http://aerosociety.com/ \\
\hline $\begin{array}{l}\text { SETI (The Search for Extraterrestrial } \\
\text { Intelligence) }\end{array}$ & http://www.seti.org/ \\
\hline Space.com & http://www.space.com/ \\
\hline
\end{tabular}

classification codes; they were identified as the major components of interplanetary travel: astrophysics, relativity and quantum fields, biophysics and medical physics, aerospace engineering, electronic and communications, and materials and condensed matter. It was a laborious process that required knowledge of the Inspec classification codes as well as knowledge of the scientific literature.

The use of co-occurring classification codes was appropriate for this study; it is also a well-known technique use to analyze bibliometric information. In bibliographic records, it is not unusual to find keywords assigned by authors that are not relevant or that fail to represent the subject of the document accurately. Classification codes represent the specialized terminology uniquely created for the subject coverage of Inspec and are assigned to the documents by expert indexers. The number of co-occurrences of two or more classification 
codes represents the frequency of documents where they appear. This phenomenon basically corresponds to the concept of small-world networks: the friends of my friends are also my friends. Therefore documents are interconnected when sharing the same classification codes. The use of the Watts-Strogatz Small World (2009) model facilitated the analysis of a large number of interconnected nodes; a model which has been considered adequate for bibliographic analysis.

In general, the identification of the six major components listed above was not a surprise, but it was a good result because it demonstrated the complexity and multidisciplinarity of the topic.

\section{REFERENCES}

AccessScience, the McGraw-Hill encyclopedia of science and technology on the web (2000). Retrieved from http://accessscience.com/

Alber, I. E. (2012). Aerospace engineering on the back of an envelope. Heidelberg: Springer.

Allen, M., Jacobs, S. K., \& Levy, J. R. (2006). Mapping the literature of nursing 1996-2000. Journal of the Medical Library Association, 94(2) 206-220.

Antuñano, M. J., \& Wade, K. (2014). Index of international publications in aerospace medicine (5th ed.). Washington, DC: Federal Aviation Administration, Office of Aerospace Medicine.

Arencibia-Jorge, R., Vega-Almeida, R. L., \& Martí-Lahera, Y. (2007). Domain analysis for the construction of a conceptual structure: A case study. LIBRES: Library \& Information Science Research Electronic Journal, 17(2), 1-26.

Assefa, S., \& Rorissa, A. (2013). A bibliometric mapping on the structure of STEM education using co-word analysis. Journal of the American Society for Information Science and Technology, 64(12), 2513-2536.

Barabási, A-L., \& Albert, R. (1999). The emergence of scaling in random networks. Science, 286, 797-817.

Bassani, G. F., Liedl, G. L., \& Wyder, P. (Eds.). (2005). Encyclopedia of condensed matter physics. Amsterdam: Elsevier.

Belter, C. W., \& Seidel, D. J. (2013). A bibliometric analysis of climate engineering research. WIREs Climate Change, 4, 417-427.

Bergström, L., \& Goobar, A. (2004). Cosmology and particle astrophysics (2nd ed.). Chichester: J. Wiley.

Bird, J. O. (2014). Electrical circuit theory and technology (5th ed.). London: Routledge, Taylor \& Francis.

Boyack, K. W., Wylie, B. N., \& Davidson, G. S. (2002). Domain visualization using VxInsight for science and technology management. Journal of the American Society for Information Science and Technology, 53(9), 764-774.

Braun, T., Glanzel W., Maczelka, H., \& Zsindely, S. (1993). Image of Analytical Chemistry as reflected in the Analytical Abstracts database: Journal coverage, concentration, and dispersion of the analytical literature, Journal of Chemical Information and Computer Sciences, 33(1) 164-173.

Buckey, J. C. (2006). Space physiology. Oxford: Oxford University Press.

Buschow, K. H. J. (Ed.). (2001). Encyclopedia of materials: Science and technology. Amsterdam: Elsevier.

Chen, C., Paul, R. J., \& O'Keefe, B. (2001). Fitting the jigsaw of citation: Information visualization in domain analysis. Journal of the American Society for Information Science and Technology, 52(4), 315-330.

Clark, S. (1999). Towards the edge of the universe: a review of modern cosmology (2nd ed.). London: Springer.

Clément, G. (2011). Fundamentals of space medicine (2nd ed.). New York: Springer.

Cleveland, W. S., \& McGill, R. (1985). Graphical perception and graphical methods for analyzing scientific data. Science, 229(4716), 828-833. 
Cleveland, W. S., \& McGill, R. (1987). Graphical perception: The visual decoding of quantitative information on graphical displays of data. Journal of the Royal Statistical Society. Series A, 150(3), 192-229.

Cobo, M. J., López-Herrera, A. G., Herrera-Viedma, E., \& Herrera, F. (2011). Science mapping software tools: Review, analysis, and cooperative study among tools. Journal of the Association for Information Science and Technology, 62(7), 1382-1402.

Collier, P. (2014). A most incomprehensible thing: Notes towards a very gentle introduction to the mathematics of relativity (2nd ed.). Harlow: Incomprehensible Books.

Cumpsty, N., \& Heyes, A. (2003). Jet propulsion: A simple guide to the aerodynamics and thermodynamic design and performance of jet engines (3rd ed.). New York: Cambridge University Press.

Davies, M. (Ed.). (2003). The standard handbook for aeronautical and astronautical engineers. New York: McGraw-Hill.

Davis, E. W. (2006). An assessment of faster-than-light spacetimes: Make or break issues. Paper presented at the 42nd AIAA/ASME/SAE/ASEE Joint Propulsion Conference \& Exhibit, Joint Propulsion Conferences, Sacramento, California, 9-12 July 2006.

Davis, E. W. (2012). Faster-than-light space warps, status and next steps. Paper presented at the 48th AIAA/ASME/SAE/ASEE Joint Propulsion Conference \& Exhibit, Joint Propulsion Conferences, Atlanta, Georgia, 30 July-1 August 2012.

Davis, J. R., Johnson, R., Stepanek, J., \& Fogarty, J. A. (Eds.). (2008). Fundamentals of aerospace medicine (4th ed.). Philadelphia: Lippincott Williams \& Wilkins.

De Bellis, N. (2009). Bibliometrics and citation analysis: From the Science Citation Index to cybermetrics. Lanham, MD: Scarecrow Press.

De Pater, I., \& Lissauer, J. J. (2015). Planetary sciences (2nd ed.). Cambridge: Cambridge University Press.

Delwiche, F. A. (2016). Reviews of science for science librarians: The challenge of the Zika virus: An emerging arbovirus disease. Science \& Technology Libraries, 35(3), 183-202.

DiBianco, P., \& Chapman, L. (2005). Literature and more... Information Searcher, 16(2), 1118.

Driggers, R. G. (Ed.). (2003). Encyclopedia of optical engineering. New York: Marcel Dekker.

Eisberg, R., \& Resnick, R. (1985). Quantum physics of atoms, molecules, solids, nuclei, and particles (2nd ed.). New York: Wiley.

Erdös, P., \& Rényi, A. (1959). On random graphs, I. Publicationes Mathematicae, 6, 290297.

Fix, J. D. (2004). Astronomy timeline. In J. D. Fix, Astronomy: Journey to the cosmic frontier (3rd ed.). New York: McGraw-Hill Higher Education. Retrieved from http://highered.mheducation.com/sites/0072482621/student_view0/astronomy_timeline .html

Fortescue, P. W., Stark, J., \& Swinerd, G. (2011). Spacecraft systems engineering (4th ed.). Hoboken, NJ: Wiley.

Fraser, G. (Ed.). (2006). The new physics for the twenty-first century. Cambridge, UK: Cambridge University Press.

Garcia-Escartin, J. C., \& Chamorro-Posada, P. (2013). Scouting the spectrum for interstellar travelers. Acta Astronautica, 85, 2-18.

Greene, B. (1999). The elegant universe: Superstrings, hidden dimensions, and the quest for the ultimate theory. New York: W.W. Norton.

Greene, B. (2005). The fabric of the cosmos: Space, time, and the texture of reality. New York: A.A. Knopf.

Hans, M. (Ed.). (2003). Encyclopedia of space science \& technology. New York: Wiley.

Hawking, S. (1988). A brief history of time: From the big bang to black holes. New York: Bantam Books.

Hitz, C. B., Ewing, J. J., \& Hecht, J. (2012). Introduction to laser technology (4th ed.). Hoboken: John Wiley \& Sons.

Holgate, S. A. (2010). Understanding solid state physics. Boca Raton: CRC Press. 
Hu, C-P., Hu, J. H., Deng, S-L., \& Liu, Y. (2013). A co-word analysis of library and information science in China. Scientometrics, 97, 369-382.

Jarrett, A. (2014). Reviews of science for science librarians: Ebola virus disease. Science \& Technology Libraries, 33(4), 303-32.

Kaku, M. (2006). Parallel worlds: A journey through creation, higher dimensions, and the future of the cosmos. New York: Doubleday.

Kitchin, C. R. (2007). Galaxies in turmoil: The active and starburst galaxies and the black holes that drive them. London: Springer.

Kulp, C. (2014). Reviews of science for science librarians: PCR: The discovery that powered the genomic revolution in modern science. Science \& Technology Libraries, 33(2), 124-142.

Kundt, W. (2001). Astrophysics: A primer. Berlin: Springer.

Lancaster, T., \& Blundell, S. (2014). Quantum field theory for the gifted amateur. New York: Oxford University Press.

Lerner, R. G. \& Trigg, G. L. (Eds.). (2005). Encyclopedia of physics (3rd ed.). Weinheim: Wiley-VCH.

Lilley, S. (1981). Discovering relativity for yourself. New York: Cambridge University Press.

Lubin, P. (2016). A roadmap to interstellar flight. Journal of the British Interplanetary Society, 69(2), 40-72.

Macdonald, M., \& Badescu, V. (Eds.). (2014). The international handbook of space technology. Heidelberg; New York: Springer.

Mahaling, R. N. (2009). A-Z biological physics. New Delhi, India: Centrum Press.

Marlow, C., Byron, L., Lento, T., \& Rosenn, I. (2009). Maintained relationships on Facebook. Retrieved from http://overstated.net/2009/03/09/maintained-relationshipson-facebook

McGraw-Hill encyclopedia of science and technology (11th ed.). (2012). New York: McGraw-Hill.

Meirelles, I. (2013). Design for information: An introduction to the histories, theories, and best practices behind effective information visualizations. Beverly, MA: Rockport Publishers.

Milgram, S. (1967). The small world problem. Psychology Today, 1(1), 61-67.

Murdin, P. (Ed.). (2001). Encyclopedia of astronomy and astrophysics. Bristol: Institute of Physics Pub.

Nicolaisen, J. (2007). Citation analysis. Annual Review of Information Science and Technology 41(1), 609-641.

Nicogossian, A. E., Huntoon, C. L., \& Pool, S. L. (2003). Space physiology and medicine (4th ed.). Philadelphia: Lea \& Fibiger.

Nwagwu, W. E. (2006). Bibliometric analysis of quantity and quality of Nigeria's biomedical literature. LIBRES: Library \& Information Science Research Electronic Journal, 16(2), $1-23$.

Ontell, V. (2003). Imagine that! Science fiction as a learning motivation. Community \& Junior College Libraries, 12(1), 57-70.

Osif, B. A. (1993). Teaching tough stuff: Science fiction futures and bibliographic instruction. Research Strategies, 11, 116-119.

Paschotta, R. (2008). Encyclopedia of laser physics and technology. Weinheim: Wiley-VCH.

Penttinen, J. T. J. (Ed.). (2015). The telecommunications handbook: Engineering guidelines for fixed, mobile, and satellite systems. Somerset, Great Britain: Wiley.

President's Science Advisory Committee (1958). Introduction to outer space. The White House. U.S. Government Printing Office, Washington D.C., March 26, 1958.

Price, D. J. D. S. (1965). Networks of scientific papers. Science 149(3683) 510-515.

Renard, C., \& Turcotte, E. (Eds.). (2010). Handbook of material science research. New York: Nova Science Publishers.

Rigden, J. S. (Ed.). (1996). Macmillan encyclopedia of physics. New York: Simon \& Schuster Macmillan.

Rolls-Royce plc. (2015). The jet engine. Chichester, West Sussex: John Wiley \& Sons. 
Rosenberg, Z. (2015). Citation analysis of M.A. theses and Ph.D. dissertations in sociology and anthropology: An assessment of library resource usage. The Journal of Academic Librarianship, 41(5), 680-688.

Sagan, C. (1980). Cosmos. New York: Random House.

Schiepers, C., \& Allen-Auerbach, M. (2006). Diagnostic nuclear medicine (2nd ed.). Berlin: Springer.

Scott, R. W. (1980). Finding materials on American popular culture in the MSU Libraries. Popular music, television, comics, popular fiction, movies (ED-207 573 How to Find Series No. 9. 1980). East Lansing, MI: Michigan State University Libraries.

Seedhouse, E. (2011). Trailblazing medicine: Sustaining explorers during interplanetary missions. New York: Springer.

Shackelford, J. F., \& Alexander, W. (Eds.). (2001). CRC materials science and engineering handbook (3rd ed.). Boca Raton, FL: CRC Press.

Siciliano, B., \& Khatib, O. (2016). Springer handbook of robotics (2nd ed.). Berlin: Springer.

Stankus, T. (2014). Reviews of science for science librarians: Microbes that make biofuels and work within fuel cells. Science \& Technology Libraries, 33(1), 71-88.

Steen, M. R. (2010). Graph theory and complex networks: An introduction. Enschede, Netherlands: Maarten van Steen.

Strobel, J., Radcliffe, D. F., Rajan, P., Nawaz, S., Luo, Y., Choi, J. H. \& Yu, J. H. (2011). Loose networks and the community of engineering education research: A definition by bibliometric standards. Paper presented at the 2011 ASEE Annual Conference \& Exposition, Vancouver, BC.

Sullivan, W. (1979). Black holes: The edge of space, the edge of time. Garden City, NY: Doubleday.

Susskind, L., \& Friedman, A. (2014). Quantum mechanics: The theoretical minimum. New York: Basic Books.

Sutton, G. P., \& Biblarz, O. (2011). Rocket propulsion elements (8th ed.). New York: John Wiley \& Sons.

Szebehely, V. G., \& Mark, H. (1998). Adventures in celestial mechanics (2nd ed.). New York: J. Wiley.

Tinder, R. F. (2007). Relativistic flight mechanics and space travel: A primer for students, engineers, and scientists. San Rafael, CA: Morgan \& Claypool Publishers.

Tran, C. (2016). Reviews of science for science librarians: Particle detectors. Science \& Technology Libraries, 35(3), 203-220.

Trigg, G. L., Vera, E. S., Greulich, W., \& Immergut, E. H. (Eds.). (1999). Encyclopedia of applied physics. Weinheim: Wiley-VCH.

Turton, R. (2000). The physics of solids. Oxford: Oxford University Press, 2000.

Vallado, D. A., \& McClain, W. D. (2013). Fundamentals of astrodynamics and applications (4th ed.). Hawthorne, CA: Microcosm Press.

Van Eck, N. J., \& Waltman, L. (2014). Visualizing bibliometric networks. In Y. Ding, R. Rousseau, \& D. Wolfram (Eds.), Measuring scholarly impact: Methods and practice, 285-320. New York: Springer.

Watts, D. J., \& Strogatz, S. H. (1998). Collective dynamics of "small-world” networks. Nature, 393(6684), 440-442.

Watts-Strogatz Small World. (2009). In Network workbench tool. User manual 1.0.0, (p. 1819). Indiana University, Bloomington, IN: Cyberinfrastructure for Network Science Center, School of Library and Information Science, Indiana University. Retrieved from http://nwb.cns.iu.edu/Docs/NWBTool-Manual.pdf (Archived by WebCite at http://www.webcitation.org/6i39QiSE7).

Webster, J. G. (Ed.). (1999). Wiley encyclopedia of electrical and electronics engineering. New York: John Wiley.

Zombeck, M. V. (2007). Handbook of space astronomy and astrophysics (3rd ed.). Cambridge: Cambridge University Press. 


\section{APPENDIX 1. CLASSIFICATION CODES, CLUSTERS COMPONENTS, MAJOR SUBJECT COMPONENTS, AND MOST CITED CODES}

The following table includes the following data:

- Column 1 (Codes) which shows in alphabetical order all the classification codes identified.

- Column 2 (Cluster) shows cluster numbers attached to the component codes.

- Column 3 (Titles) shows Inspec assigned titles of codes.

- Column 4 (Group) shows major subject components attached to codes and identified by colors.

- Column 5 (Most cited codes) shows the most cited codes covering $60 \%$ of all cited codes, and identified by colors as members of major subject components.

Columns 4 and 5 present some new classification codes. In the case of Column 4, these new codes are of the higher level but related to the codes found in the 10 initial clusters. The additional codes in Column 5 are those which are part of the $60 \%$ threshold but that were not present in the 10 initial clusters. The note at the end of the table establishes the relationship between the color codes and the major subject components.

\begin{tabular}{|c|c|c|c|c|}
\hline Code & Cluster & Title & Group & $\begin{array}{l}\text { Most cited } \\
\text { codes }\end{array}$ \\
\hline A01 & & Communication, education, history, and philosophy & & \\
\hline A0130C & & Conference proceedings & & 7 \\
\hline A0130E & 5 & Monographs, and collections & & \\
\hline A0150 & & Educational aids & & 10 \\
\hline A02 & & Mathematical methods in physics & & \\
\hline A0210 & & Algebra, set theory, and graph theory & & 13 \\
\hline A0240 & & Geometry, differential geometry, and topology & & 61 \\
\hline A0250 & 8 & Probability theory, stochastic processes, and statistics & & \\
\hline A0260 & 5 & Numerical approximation and analysis & & 3 \\
\hline A03 & & Classical and quantum physics; mechanics and fields & Group 1 & \\
\hline A0330 & & Special relativity & Group 1 & 17 \\
\hline A0365 & & Quantum theory; quantum mechanics & Group 1 & 6 \\
\hline A0365B & 4 & $\begin{array}{l}\text { Foundations, theory of quantum measurement, } \\
\text { miscellaneous quantum theories }\end{array}$ & Group 1 & 7 \\
\hline $\mathrm{A} 04$ & & Relativity and gravitation & Group 1 & \\
\hline A0420 & & General relativity & Group 1 & 22 \\
\hline A0420C & 4 & $\begin{array}{l}\text { Fundamental problems and general formalism in } \\
\text { general relativity }\end{array}$ & Group 1 & 47 \\
\hline A0420J & 4 & Solutions to equations in general relativity & Group 1 & 31 \\
\hline $\begin{array}{l}\text { A0420 } \\
\text { M }\end{array}$ & 5 & $\begin{array}{l}\text { Conservation laws and equations of motion in } \\
\text { general relativity }\end{array}$ & Group 1 & 5 \\
\hline A0430 & 5 & Gravitational waves and radiation: theory & Group 1 & 3 \\
\hline A0440 & 5 & $\begin{array}{l}\text { Continuous media; electromagnetic and other mixed } \\
\text { gravitational systems }\end{array}$ & Group 1 & 6 \\
\hline A0455 & 4 & Alternative theories of gravitation & Group 1 & 8 \\
\hline A0460 & & Quantum theory of gravitation & Group 1 & 48 \\
\hline A0470 & 4 & Physics of black holes & Group 1 & 21 \\
\hline A06 & & $\begin{array}{l}\text { Measurement science, general lab. techniques, and } \\
\text { instrumentation systems }\end{array}$ & & \\
\hline $\mathrm{A} 0620 \mathrm{H}$ & 7 & Measurement standards and calibration & Group 1 & \\
\hline A11 & & General theory of fields and particles & Group 1 & \\
\hline A1110 & 5 & Quantum theory & Group 1 & 6 \\
\hline $\mathrm{A} 1110 \mathrm{~N}$ & & Gauge filled theories & Group 1 & 16 \\
\hline A12 & & Specific theories and interac. models; particle systemat. & & \\
\hline A1220D & & $\begin{array}{l}\text { Specific calculations and limits of quantum } \\
\text { electrodynamics }\end{array}$ & & 17 \\
\hline A20 & & Nuclear physics & & \\
\hline A24 & & Nuclear reactions and scattering: general & & \\
\hline A2475 & 2 & General properties of fission & & \\
\hline
\end{tabular}




\begin{tabular}{|c|c|c|c|c|}
\hline A29 & & $\begin{array}{l}\text { Experimental methods and instrumentation for } \\
\text { elementary-particle and nuclear physics }\end{array}$ & & \\
\hline A2940P & 7 & Semiconductor detectors & & \\
\hline A40 & & Fundamental areas of phenomenology & & \\
\hline A42 & & Optics & Group 4 & \\
\hline A4250 & 4 & Quantum optics & Group 4 & 9 \\
\hline A4250V & 2 & Mechanical effects of light & Group 4 & \\
\hline A4255 & 3 & Lasing processes & Group 4 & \\
\hline A4255P & 1 & Lasing action in semiconductors & Group 4 & \\
\hline A4260 & 3 & Laser optical systems: design and operation & Group 4 & \\
\hline $\mathrm{A} 4260 \mathrm{H}$ & 1 & Laser optical systems: design and operation & Group 4 & \\
\hline A4262 & & Laser applications & Group 4 & 6 \\
\hline A4280 & 1 & Optical & Group 4 & \\
\hline A4280A & 1 & Optical lenses and mirrors & Group 4 & \\
\hline A4280F & 1 & Gratings, echelles & Group 4 & \\
\hline A4280S & 1 & $\begin{array}{l}\text { Optical communication devices, equipment and } \\
\text { systems }\end{array}$ & Group 4 & \\
\hline A4281 & 3 & Fiber optics and fiber waveguides & Group 4 & \\
\hline A4284 & 3 & Nanophotonic devices and technology & Group 4 & \\
\hline A4285C & 1 & Optical testing and workshop techniques & Group 4 & \\
\hline A4285D & 1 & Optical fabrication, surface grinding & Group 4 & \\
\hline A4285F & & Optical testing techniques & Group 4 & \\
\hline A60 & & $\begin{array}{l}\text { Condensed matter: structure, thermal and mechanical } \\
\text { properties }\end{array}$ & Group 6 & \\
\hline $\mathrm{A} 6020 \mathrm{H}$ & 7 & Code name not available & Group 6 & \\
\hline A61 & & Structure of liquids and solids; crystallography & Group 6 & \\
\hline A6180 & 7 & Radiation damage and other irradiation effect & Group 6 & \\
\hline A62 & & $\begin{array}{l}\text { Mechanical and acoustic properties of condensed } \\
\text { matter }\end{array}$ & Group 6 & \\
\hline A6220P & 10 & Tribology & Group 6 & \\
\hline A68 & & Surfaces and interfaces; thin films and whiskers & Group 6 & \\
\hline A6825 & 10 & $\begin{array}{l}\text { Mechanical and acoustical properties of solid surfaces } \\
\text { and interfaces }\end{array}$ & Group 6 & \\
\hline A6860 & 10 & Physical properties of thin films, nonelectronic & Group 6 & \\
\hline A81 & & Materials science & Group 6 & \\
\hline $\mathrm{A} 8140 \mathrm{~N}$ & 10 & Physical properties of thin films, nonelectronic & Group 6 & \\
\hline A8140P & 10 & Friction, lubrication, and wear & Group 6 & \\
\hline A8160B & 10 & Surface treatment and degradation of metals and alloys & Group 6 & \\
\hline A82 & & Physical chemistry & Group 6 & \\
\hline A8265N & 10 & Other gas-surface interactions (surface chemistry) & Group 6 & \\
\hline A86 & & Energy research and environmental science & Group 3 & \\
\hline A8610D & 6 & Wind energy & Group 3 & \\
\hline $\mathrm{A} 8610 \mathrm{~N}$ & 2 & Nuclear energy & Group 3 & \\
\hline A8630J & & Photoelectric conversion; solar cells and arrays & Group 3 & 7 \\
\hline $\mathrm{A} 8630 \mathrm{~N}$ & 2 & Thermionic conversion & Group 3 & \\
\hline A8640K & 6 & Hydrogen storage and technology & Group 3 & \\
\hline A87 & & $\begin{array}{l}\text { Biophysics, medical physics, and biomedical } \\
\text { engineering }\end{array}$ & Group 2 & \\
\hline A8715M & & Interactions with radiations at the biomolecular level & Group 2 & 7 \\
\hline A8725 & & Cellular biophysics & Group 2 & 11 \\
\hline A8745F & 7 & Rheology of body fluids & Group 2 & \\
\hline A8750G & & $\begin{array}{l}\text { Biological effects of ionizing radiations (UV, X-ray, } \\
\text { gamma-ray; particle radiation effects) }\end{array}$ & Group 2 & 20 \\
\hline A8760 & 8 & $\begin{array}{l}\text { Medical and biomedical uses of fields, radiations, and } \\
\text { radioactivity; health physics }\end{array}$ & Group 2 & \\
\hline A8760B & 7 & Sonic and ultrasonic radiation (medical uses) & Group 2 & \\
\hline A8760I & & Medical magnetic resonance imaging and spectroscopy & Group 2 & \\
\hline A8760K & & Nuclear medicine, emission tomography & Group 2 & \\
\hline
\end{tabular}




\begin{tabular}{|c|c|c|c|c|}
\hline \multirow{2}{*}{\multicolumn{2}{|c|}{$\begin{array}{l}\text { A8760M } \\
\text { A8765 }\end{array}$}} & Radiation dosimetry in medical physics & Group 2 & 8 \\
\hline & & $\begin{array}{l}\text { Aerospace biophysics and medical physics (effects of } \\
\text { accelerations, weightlessness and environment) }\end{array}$ & Group 2 & 36 \\
\hline A8770E & & Patient diagnostic methods and instrumentation & Group 2 & 6 \\
\hline $\mathrm{A} 8770 \mathrm{H}$ & 8 & Radiation therapy & Group 2 & \\
\hline A94 & & Aeronomy, space physics, and cosmic rays & Group 5 & \\
\hline A9440C & 7 & $\begin{array}{l}\text { Cosmic ray origin and propagation outside the solar } \\
\text { system }\end{array}$ & Group 5 & \\
\hline A9460Q & 9 & $\begin{array}{l}\text { Solar wind interaction with Moon, planets, satellites, } \\
\text { and comets }\end{array}$ & Group 5 & \\
\hline A9480 & & $\begin{array}{l}\text { Instrumentation and techniques for aeronomy, space } \\
\text { physics, and cosmic rays }\end{array}$ & Group 5 & 19 \\
\hline A95 & & $\begin{array}{l}\text { Fundamental astronomy and astrophysics, } \\
\text { instrumentation and techniques and astronomical } \\
\text { observations }\end{array}$ & Group 5 & \\
\hline A9510 & 5 & Fundamental astronomy & Group 5 & \\
\hline A9510C & 3 & Celestial mechanics & Group 5 & \\
\hline A9530C & 5 & $\begin{array}{l}\text { Elementary particle and nuclear processes in } \\
\text { astrophysics }\end{array}$ & Group 5 & \\
\hline A9530S & & Relativity and gravitation in astrophysics & Group 5 & 55 \\
\hline A9555 & & Astronomical and space-research instrumentation & Group 5 & 7 \\
\hline A9555J & 9 & Radiotelescopes & Group 5 & \\
\hline A9555L & 3 & Aerospace instrumentation & Group 5 & 7 \\
\hline A9555P & 3 & Lunar, planetary, and deep-space probes & Group 5 & 49 \\
\hline A9575 & & Astronomical techniques & Group 5 & 9 \\
\hline A9590 & & Other topics in astronomy and astrophysics & Group 5 & 35 \\
\hline A96 & & Solar system & Group 5 & \\
\hline A9620 & 2 & Moon & Group 5 & \\
\hline A9620D & 2 & Lunar interior, surface, and atmosphere & Group 5 & \\
\hline A9630G & 2 & Mars and satellites & Group 5 & \\
\hline $\mathrm{A} 9630 \mathrm{H}$ & & Asteroids & Group 5 & \\
\hline A9630K & 3 & Jupiter and satellites & Group 5 & \\
\hline A9630M & 3 & Saturn and satellites & Group 5 & \\
\hline A9635G & 2 & Planetary surfaces and topography; tectonics & Group 5 & \\
\hline A9660 & 9 & Solar physics & Group 5 & \\
\hline A9660S & 9 & Solar prominences and mass ejections & Group 5 & \\
\hline A9660V & 3 & Solar particle radiation, solar wind & Group 5 & \\
\hline A97 & & Stars & Group 5 & \\
\hline A9720G & 9 & Main-sequence: intermediate type A and F stars & Group 5 & \\
\hline A9760L & 4 & Black holes & Group 5 & 19 \\
\hline A98 & & $\begin{array}{l}\text { Stellar systems; Galactic and extragalactic objects and } \\
\text { systems; Universe }\end{array}$ & Group 5 & \\
\hline A9850T & 4 & Intergalactic and intracluster matter & Group 5 & \\
\hline A9870V & & Background cosmic radiations & Group 5 & 8 \\
\hline A9880 & & Cosmology & Group 5 & 10 \\
\hline A9880B & 5 & Origin and early evolution of the Universe & Group 5 & \\
\hline A9880D & & Theoretical cosmology & Group 5 & 42 \\
\hline B01 & & General electrical engineering topics & & \\
\hline B0160 & 2 & Plant engineering, maintenance and safety & & \\
\hline B0170 & 6 & Project and production engineering & & \\
\hline B0170G & & General fabrication techniques & & \\
\hline B0170N & 2 & Reliability & & \\
\hline B02 & & Engineering mathematics and mathematical techniques & & \\
\hline B0240G & 8 & Monte Carlo methods & & \\
\hline B0240Z & 8 & Other topics in statistics & & \\
\hline $\mathrm{B} 10$ & & Circuit theory and circuits & Group 4 & \\
\hline B11 & & Circuit theory & Group 4 & \\
\hline B1110 & 6 & Network topology & Group 4 & \\
\hline
\end{tabular}




\begin{tabular}{|c|c|c|c|c|}
\hline B12 & & Electronic circuits & Group 4 & \\
\hline B1205 & 6 & Analogue circuit design, modeling and testing & Group 4 & \\
\hline B1220 & 6 & Amplifiers & Group 4 & \\
\hline B13 & & Microwave technology & Group 4 & \\
\hline B1350 & 6 & Microwave circuits and devices & Group 4 & \\
\hline $\mathrm{B} 2570 \mathrm{D}$ & 1 & CMOS integrated circuits & Group 4 & \\
\hline $\mathrm{B} 40$ & & $\begin{array}{l}\text { Optical materials and applications, electro-optics and } \\
\text { optoelectronics }\end{array}$ & Group 4 & \\
\hline B41 & & Optical materials and devices & Group 4 & \\
\hline B4146 & 3 & Nanophotonic devices and technology & Group 4 & \\
\hline B43 & & Lasers and masers & Group 4 & \\
\hline B4320 & 1 & Lasers & Group 4 & \\
\hline B4330B & 1 & $\begin{array}{l}\text { Laser beam modulation, pulsing and switching; mode } \\
\text { locking and tuning }\end{array}$ & Group 4 & \\
\hline B4360 & & Laser applications & Group 4 & 14 \\
\hline $\mathrm{B} 60$ & & Communications & Group 4 & \\
\hline B61 & & Information and communication theory & Group 4 & \\
\hline B6140 & 9 & Signal processing and detection & Group 4 & \\
\hline B62 & & Telecommunication & Group 4 & \\
\hline B6260S & 1 & Free-space optical links & Group 4 & \\
\hline B63 & & Radar and radionavigation & Group 4 & \\
\hline B6320C & 1 & Optical radar & Group 4 & \\
\hline B75 & & Medical physics and biomedical engineering & Group 2 & \\
\hline $\mathrm{B} 7510 \mathrm{H}$ & 7 & $\begin{array}{l}\text { Sonic and ultrasonic radiation (biomedical } \\
\text { imaging/measurement) }\end{array}$ & Group 2 & \\
\hline B7510P & 8 & $\begin{array}{l}\text { X-ray techniques: radiography and computed } \\
\text { tomography (biomedical imaging/measurement) }\end{array}$ & Group 2 & \\
\hline B7520C & 8 & Radiation therapy & Group 2 & \\
\hline B76 & & Aerospace facilities and techniques & Group 3 & \\
\hline B7600 & & Aerospace facilities and techniques & Group 3 & 7 \\
\hline B7610 & & General aspects of aircraft, space vehicles and satellites & Group 3 & 36 \\
\hline B7630 & 3 & Health physics & Group 3 & 4 \\
\hline B7640 & & Aerospace propulsion & Group 3 & 54 \\
\hline B78 & & Sonics and ultrasonics & Group 3 & \\
\hline B7820 & 7 & Sonic and ultrasonic applications & Group 3 & \\
\hline B7900 & 2 & Military systems and equipment & Group 3 & \\
\hline B82 & & Generating stations and plants & Group 3 & \\
\hline B8220 & 2 & Nuclear power stations and plants & Group 3 & \\
\hline B84 & & Direct energy conversion and energy storage & Group 3 & \\
\hline B8460 & 2 & Other direct energy conversion & Group 3 & \\
\hline C33 & & Control applications & Group 3 & \\
\hline C3350Z & 2 & Control applications in other industries & Group 3 & \\
\hline C3360L & & Aerospace control & Group 3 & 12 \\
\hline C3370R & 1 & Control applications in optical communication & Group 3 & \\
\hline C61 & & Software techniques and systems & & \\
\hline $\mathrm{C} 6170 \mathrm{~T}$ & 7 & Knowledge engineering tools & & \\
\hline C6180 & 9 & User interfaces & & 2 \\
\hline C7460 & & Aerospace engineering computing & Group 3 & 10 \\
\hline E1030 & 6 & Research and development & & \\
\hline E1550A & 2 & Robotics & & \\
\hline E1810 & 6 & Products and commodities & & \\
\hline E2320 & & Engines & Group 3 & 8 \\
\hline E3050 & 2 & Service industries & & \\
\hline E3650C & & Aerospace industry & Group 3 & 23 \\
\hline
\end{tabular}

Group 1 = Green = relativity and quantum physics; Group 2 = Red = biophysics, medical physics;

Group 3 = Blue = aerospace engineering; Group 4 = Gray = electronics, communications;

Group 5 = Purple $=$ astrophysics; Group $6=$ Orange $=$ materials science, condensed matter 


\section{APPENDIX 2. BOOKS AND CONFERENCE PROCEEDINGS CITED}

Books Cited with Publication Dates From 2001 to 1967

\begin{tabular}{|c|c|c|}
\hline Author, Title & Publisher & Year \\
\hline $\begin{array}{l}\text { Milonni, P. W. The Quantum Vacuum: An Introduction to } \\
\text { Quantum Electrodynamics }\end{array}$ & Academic Press & 1994 \\
\hline $\begin{array}{l}\text { Thorne, K. S. Black Holes \& Time Warps: Einstein's } \\
\text { Outrageous Legacy }\end{array}$ & W. W. Norton \& Co. & 1994 \\
\hline $\begin{array}{l}\text { Halpern, P. Cosmic wormholes: the search for interstellar } \\
\text { shortcuts }\end{array}$ & Plume & 1993 \\
\hline Hawking, S.W. Hawking on the big bang and black holes & World Scientific & 1993 \\
\hline $\begin{array}{l}\text { Saleh, B. E. A., and Teich, M. C. Fundamentals of } \\
\text { Photonics }\end{array}$ & John Wiley \& Sons & 1991 \\
\hline $\begin{array}{l}\text { Saunders, S.; and Brown, H. R.; editors. The Philosophy of } \\
\text { Vacuum }\end{array}$ & Clarendon Press & 1991 \\
\hline Barrow, J.D.; Tipler, F.J. Anthropic cosmological principle & Clarendon Press & 1986 \\
\hline $\begin{array}{l}\text { Birrell, N. D., and Davies, P. C. W. Quantum fields in } \\
\text { curved space }\end{array}$ & Cambridge University Press & 1984 \\
\hline $\begin{array}{l}\text { Jasani, B.; editor. Outer space - A new dimension of the } \\
\text { arms race }\end{array}$ & Taylor \& Francis & 1982 \\
\hline $\begin{array}{l}\text { Hawking, S. W.; Ellis, G. F. R. The Large-Scale Structure } \\
\text { of Space-Time }\end{array}$ & Cambridge University Press & 1973 \\
\hline $\begin{array}{l}\text { Page, T.; Page, L.W.; editors. Wanderers in the Sky: The } \\
\text { motions of planets and space probes }\end{array}$ & Macmillan & 1967 \\
\hline
\end{tabular}

\section{Conference Proceedings Cited with Publication Date From 2015 to 1969}

\begin{tabular}{l} 
Listed by the title of the conference \\
\hline 2015 IEEE International Conference on Plasma Sciences (ICOPS), Belek, Antalya, Turkey, May \\
24-28, 2015. IEEE Conference Proceedings. Piscataway, NJ: IEEE, 2015. \\
\hline 2015 IEEE Scientific Visualization Conference (SciVis), 25-30 Oct. 2015 Chicago, IL, IEEE \\
Conference Proceedings. Piscataway, NJ: IEEE, 2015. \\
Nanophotonics and macrophotonics for space environments IX, 10-11 August 2015, San Diego, \\
CA, USA. Taylor, Edward W.; Cardimona, David A., editors. Proc. of SPIE Vol. 9616, Bellingham, \\
WA: SPIE, 2015. \\
\hline AIAA Space 2015 Conference and Exposition, 31 Aug-2 Sep 2015, Pasadena, CA, American \\
Institute of Aeronautics and Astronautics, Red Hook, NY Curran, 2015 \\
\hline 1st Stardust Global Virtual Workshop (SGVW-1) on Asteroids and Space Debris, 6-9 May 2014, \\
Glasgow, Scotland. Advances in Space Research. In press, 2016. \\
\hline Nanophotonics and macrophotonics for space environments VIII, 18-19 August 2014, San Diego, \\
CA, USA. Taylor, Edward W.; Cardimona, David A., editors. Proc. of SPIE Vol. 9226, Bellingham, \\
WA: SPIE, 2015. \\
\hline 41st annual review of progress in quantitative nondestructive evaluation, 20-25 July 2014, Boise, \\
ID, Dale E Chimenti; Leonard J Bond. AIP conference proceedings, 1650, Melville, New York: AIP \\
Publishing, 2015. \\
\hline Dynamics and control of space systems DyCoSS2014, proceedings of the 2nd International \\
Academy of Astronautics Conference on Dynamics and Control of Space Systems (DyCoSS), \\
March 24-26, 2014, Rome, Italy, Filippo Graziani; Anna D Guerman; Jean-Michel Contant. \\
Advances in the astronautical sciences, 153, San Diego: Univelt, 2015. \\
\hline 2014 IEEE Aerospace Conference, Big Sky, Montana, March 1-8, 2014. IEEE Conference \\
Proceedings, Piscatawy NJ: IEEE, 2014. \\
32nd AIAA International communications satellite systems conference 2014, held at the AIAA \\
Space forum 2014: San Diego, CA, 4-7 August 2014. Reston, VA: AIAA, 2014. \\
49th AIAA/ASME/SAE/ASEE joint propulsion conference, July 28-30, 2014, Cleveland, OH. Reston, \\
VA: American Institute of Aeronautics and Astronautics, 2014. \\
\hline AIAA SPACE Conference and Exposition 2014, San Diego, California, USA, 4-7 August 2014. \\
\hline
\end{tabular}


American Institute of Aeronautics and Astronautics, Red Hook, NY Curran, 2014.

A safer space for a safer world, proceedings of the 6th IAASS conference. 21-23 May 2013,

Montreal, Canada. L Ouwehand, Paris, France: European Space Agency, 2013.

AIAA SPACE conference \& exposition 2013. San Diego, California, USA, 10-12 September 2013,

Reston, VA: American Institute of Aeronautics and Astronautics, 2013.

Nanophotonics and macrophotonics for space environments VII, 25-27 August 2013, San Diego,

CA, United States. Taylor, Edward W.; Cardimona, David A., editors. Proc. of SPIE Vol. 8876,

Bellingham, WA: SPIE, 2013.

5th International Conference on Recent Advances in Space Technologies (RAST), 9-11 June 2011,

Istanbul, Turkey. IEEE Conference Proceedings. Piscataway, NJ: IEEE, 2011.

A safer space for a safer world, proceedings of the 6th IAASS conference, 17-19 October 2011,

Versailles, France. L Ouwehand, Noordwijk, The Nederlands: ESA Communications, 2011.

Dark matter in astrophysics and particle physics, proceedings of the 7th International Heidelberg

Conference, Dark 2009, Christchurch, New Zealand, 18-24 January 2009. Klapdor-Kleingrothaus,

H.V., Singapore: World Scientific, 2010.

Space, Propulsion \& Energy Sciences International Forum, SPESIF-2010, Johns Hopkins-APL,

Laurel, Maryland, 23-25 February 2010, 14th Conference on Thermophysics Applications in

Microgravity, 7th Symposium on New Frontiers in Space Propulsion Sciences, 2nd Symposium on

Astrosociology, 1st Symposium on High Frequency Gravitational Waves, Meeting on Future

Directions in Space Sciences \& Technology, Workshop on Future Energy Sources. Johns Hopkins-

APL, Laurel, Maryland, 21-23 February 2010. AIP Conference Proceedings. Glen A Robertson,

Melville, NY: American Institute of Physics, 2010.

3rd IAASS conference: Building a safer space together: 21-23 October 2008, Rome, Italy. Huguette

Lacoste; L. Ouwehand. Noordwijk, The Netherlands: ESA Communication Production Office, 2009.

Frontiers of Propulsion Science, M. G. Millis and E. W. Davis, editors. Progress in Astronautics and Aeronautics Vol. 227. VA: AIAA Press, 2009.

Space, Propulsion \& Energy Sciences International Forum, SPESIF-2009 : 13th Conference on

Thermophysics Applications in Microgravity, 6th Symposium on New Frontiers in Space

Propulsion Sciences, 1st Symposium on Astrosociology, Workshop on Future Energy Sources,

Workshop on High Frequency Gravitational Waves, Workshop on Future Directions in Space

Sciences \& Technology: Huntsville, Alabama, 24-26 February 2009. AIP Conference Proceedings.

Glen A Robertson, Melville, NY: American Institute of Physics, 2009.

Robotics and Automation, 2008, ICRA 2008, IEEE International Conference, 19-23 May, 2008.

IEEE Conference Proceedings, Piscataway, NJ: IEEE, 2008.

Space Technology and Applications International Forum, STAIF 2008: 12th Conference on

Thermophysics Applications in Microgravity; 1st Symposium on Space Resource Utilization ; 25th

Symposium on Space Nuclear Power and Propulsion ; 6th Conference on Human/Robotic

Technology and the Vision for Space Exploration; 6th Symposium on Space Colonization; 5th

Symposium on New Frontiers and Future Concepts: Albuquerque, New Mexico, 10-14 February

2008. AIP Conference Proceedings, El-Genk, Mohamed S. Melville, NY: American Institute of

Physics, 2008.

Transactions of the American Nuclear Society and Embedded Topical Meetings Isotopes for

Medicine and Industry and Nuclear Fuels and Structural Materials for the Next Generation Nuclear

Reactors (NFSM), June 8-12, 2008, Anaheim, California, Stephen P LaMont; Julie B Rule; Ellen M

Leitschuh. Transactions of the American Nuclear Society, vol. 98, La Grange Park, IL: American

Nuclear Society, 2008.

2006 IEEE Aerospace Conference: Big Sky, Montana, 4-11 March 2006. IEEE Conference

Proceedings. Piscataway, NJ: IEEE, 2007.

2007 IEEE Aerospace Conference: Big Sky, MT, 3-10 March 2007. IEEE Conference Proceedings.

Instruments, methods, and missions for astrobiology X, 28-30 August 2007, San Diego, CA,

Richard B Hoover, Proceedings of SPIE v. 6694. Piscataway, NJ: IEEE, 2007.

Sensors and systems for space applications, 9-11 April, 2007, Orlando, FL, Richard T Howard;

Robert D Richards, Proceedings of SPIE v. 6694. Bellingham, WA SPIE, 2007.

Beamed energy propulsion, Fourth International Symposium on Beamed Energy Propulsion, Nara,

Japan, 15-18 November 2005, Kimiya Komurasaki, AIP conference proceedings, no. 830. Melville,

NY: American Institute of Physics, 2006.

Guidance and control 2006, proceedings of the 29th annual AAS Rocky Mountain Guidance and

Control Conference held February 4-8, 2006, Breckenridge, CO, Steven D Jolly; Robert D Culp. 
Advances in astronautical sciences, v. 125, San Diego: American Astronautical Society, 2006. High-power laser ablation VI, 7-12 May, 2006, Taos, New MX, Claude R Phipps, Proceedings of SPIE v. 6261. Bellingham, WA: SPIE, 2006.

Proceedings of the STAIF-2006: 3rd Symposium on New Frontiers and Future Concepts, edited by M. S. El-Genk, AIP Conf. Proc. Vol. 813, New York: AIP Press, 2006.

Space Technology and Applications International Forum, STAIF 2006 : 10th Conference on Thermophysics Applications in Microgravity, 23rd Symposium on Space Nuclear Power and Propulsion, 4th Conference on Human/Robotic Technology and the National Vision for Space Exploration, 4th Symposium on Space Colonization, 3rd Symposium on New Frontiers and Future Concepts : Albuquerque, New Mexico, 12-16 February 2006. AIP Conference Proceedings, ElGenk, Mohamed S. Melville, NY: American Institute of Physics, 2006.

Visual information processing XV. 18-19 April, 2006, Kissimmee, FL, Zia-ur Rahman; Stephen E Reichenbach; Mark A Neifeld, Proceedings of SPIE 6246. Bellingham, WA: SPIE, 2006.

Proceedings of the First IAASS Conference: Space Safety, a New Beginning: 25-27 October 2005, Nice, France. H Lacoste. Noordwijk, The Netherlands: ESA Publications Division, 2005.

2004 NASA/DoD Conference on Evolvable Hardware proceedings, June 24-26, 2004, Seattle, Washington, USA. Ricardo S Zebulum, Los Alamitos, CA: IEEE Computer Society, 2004.

Third International Conference on Inertial Fusion Sciences and Applications, 7-12, 2003, Monterey, CA, B. A. Hammel. La Grange Park, IL: American Nuclear Society, 2004.

A relativistic spacetime odyssey. Proceedings, 25th Johns Hopkins Workshop on Problems in particle theory, Florence, Italy, September 3-5, 2001. Ciufolini, I.; Dominici, D.; Lusanna, L., River Edge, NJ: World Scientific, 2003.

Beamed energy propulsion, First International Symposium on Beamed Energy Propulsion, Huntsville, Alabama, 5-7 November, 2002, Andrew V Pakhomov, AIP conference proceedings, no. 664. Melville, NY: American Institute of Physics, 2003.

Davis Inflation Meeting, March 22-25, 2003. Index of the Davis Cosmic Inflation Meeting Proceedings. Unpublished, 2003.

Proceedings of the 5th ESA International Conference on Spacecraft guidance, navigation and control systems, Frascati, Italy, 22-25 October 2002, Robert A Harris; ESA SP, 516. Noordwijk, The Nederlands: European Space Agency, 2003.

2002 IEEE Aerospace Conference Proceedings. Big Sky, Montana, March 9-16, 2002. Karen J Profet; G Edward Bryan; Sohrab Mobasser; David A Williamson. IEEE Conference Proceedings, 2002.

EMBS 2002 BMES, Conference proceedings. Second Joint EMBS-BMES Conference 2002, 24th Annual International Conference of the Engineering in Medicine and Biology Society, Annual Fall Meeting of the Biomedical Engineering Society: bioengineering--integrative methodologies, new technologies, 23-26 October 2002, Houston, TX, John W Clark; Larry V McIntire. IEEE Proceedings, Piscataway, NJ: IEEE, 2002.

Space Technology and Applications International Forum - STAIF 2002 : Conference on Thermophysics in Microgravity ; Conference on Innovative Transportation Systems for Exploration of the Solar System and Beyond ; 19th Symposium on Space Nuclear Power and Propulsion ; Conference on Commercial/Civil Next Generation Space Transportation ; Albuquerque, New Mexico, 3 - 6 February 2002. AIP Conference Proceedings, El-Genk, Mohamed S. Melville, NY: American Institute of Physics, 2002.

Cosmo International Conference on Particle Physics and Cosmology, Cosmo2001, Rovaniemi, Finland, 30-4 September, 2001. Unpublished, 2001.

International Symposium on Microelectronics, Proceedings, October 9-11, 2001, Baltimore, Maryland SPIE Proceedings, vol. 4587. Washington, DC: IMAPS 2001.

International Workshop on Models for Evaluation of Radiation Risk Factors. Houston, TX, USA. Radiation Research, vol.156, no.5, pt. 2, Nov. 2001.

Space Technology and Applications International Forum - 2001: Conference on Space Exploration

Technology ; Conference on Thermophysics in Microgravity; Conference on Innovative Transportation Systems for Exploration of the Solar System and Beyond; Conference on Commercial/Civil Next Generation Space Transportation; 18th Symposium on Space Nuclear Power and Propulsion ; Space radiation and environmental effects track ; Albuquerque, New Mexico, 11 - 14 February 2001. AIP Conference Proceedings, El-Genk, Mohamed S. Melville, NY: American Institute of Physics, 2001.

1999 IEEE Aerospace Conference, proceedings, David F Woerner; Robert A Profet; Robert P Wright; G Edward Byran; Sohrab Mobassar. IEEE Proceedings, Piscataway, NJ: IEEE, 2000. 
American Nuclear Society 2000 annual meeting, San Diego, California, June 4-8, 2000.

Lagrangian and Hamiltonian methods for nonlinear control, a proceedings volume from the IFAC Workshop, Princeton, New Jersey, USA, 16-18 March 2000, Naomi Ehrich Leonard; Romeo Ortega. Oxford; New York: Pergamon, 2000.

Transactions of the American Nuclear Society 2000, vol.82. La Grange Park, IL: American Nuclear Society, 2000.

Instruments, methods, and missions for astrobiology, 20-22 July 1998, San Diego, CA, Richard B Hoover, Proceedings of SPIE v. 3441. Bellingham, WA: SPIE, 1998.

Progress in the search for extraterrestrial life, 1993 Bioastronomy Symposium, Santa Cruz, CA, 1620 August 1993. G Seth Shostak. Astronomical Society of the Pacific (ASP) conference series v. 74. San Francisco, CA. Astronomical Society of the Pacific, 1993.

Living and working in space, 9th Man in space symposium, Cologne, Germany. Acta Astronautica, vol. 27, 1992.

Ninth Symposium on Space Nuclear Power Systems, Proceedings, Albuquerque, NM, January 1216, 1992, Mohamed S el- El-Genk, AIP conference proceedings 246, New York: American Institute of Physics, 1992.

Second International Symposium. Particles, Strings and Cosmology. Boston, MA, USA, Nath, P.; Reucroft, S. Singapore; Boston, MA: World Scientific, 1992.

Seventh Symposium on Space Nuclear Power Systems, Proceedings, Albuquerque, NM, January 710, 1990, Mohamed S El-Genk; Mark D Hoover. Albuquerque, NM: Institute for Space Nuclear Power Studies, 1990.

International Academy of Astronautics Interstellar Space Flight Session of the 36th International Astronautical Congress. Stockholm, Sweden, 1985. Journal of the British Interplanetary Society, vol.39, no. 9, 1986.

Life sciences and space research XXII. Proceedings of the Topical Meeting of the COSPAR Interdisciplinary Scientific Commission F (Meeting F1, F3, F4, F5 and F9) and of Workshop IV of the COSPAR Twenty-sixth Plenary Meeting held in Toulouse, France, 30th June-11th July 1986. Advances in Space Research vol. 6, no.11, 1986.

Life sciences and space research XXI. Proceedings of the Topical Meeting of the COSPAR Interdisciplinary Scientific Commission F (Meetings F4 and F8) of the COSPAR Twenty-fifth Plenary Meeting held in Graz, Austria, 25th June-7th July 1984. Advances in Space Research vol.4, no.10, 1984.

Proceedings of the 8th International Conference on Medical and Biological Engineering and the 22nd annual Conference on Engineering in Medicine and Biology, including the 4th annual meeting of the AAMI, 1969, Chicago, Illinois, J E Jacobs. Chicago: Chicago Conference Committee, 1969. 